\title{
Nombrando las desviaciones para fijar adhesiones. Una interpretación de las circulaciones de la herejía y de la condena a los herejes desde la ciudad de Bogotá, $1819-1826^{1}$
}

\author{
Circulation, appropriation and experience of schism and \\ heresy in the city of Bogotá, 1819-1826. Initial suggestions \\ for an interpretation
}

Doi:10.25100/hye.v17i56.11256

Artículo recibido:01-07-2020. Artículo aceptado:26-03-2021

\section{Jeferson Jesid Díaz Sastre}

Universidad Nacional de Colombia

Correo electrónico: jjdiazs@unal.edu.co

ORCID: https://orcid.org/0000-0003-1149-2621

Forma de citar este artículo: Díaz Sastre, Jefferson. "Nombrando las desviaciones para fijar adhesiones. Una interpretación de las circulaciones de la herejía y de la condena a los herejes desde la ciudad de Bogotá, 1819-1826”. Historia y Espacio, vol. 17, n56 (2021):Pag. Doi.org/10.25100/hye.v17i56.11256

1 Artículo Tipo 2: de reflexión. Las ideas aquí expresadas comienzan a tomar forma desde el año 2017 en el marco del Congreso Internacional «Política y religión en el siglo XIX hispanoamericano: una aproximación desde la historia intelectual y conceptual», evento académico organizado por el Departamento de Historia y el Centro de Estudios Sociales (CES) de la Facultad de Ciencias Humanas de la Universidad Nacional de Colombia, sede Bogotá, junto con la Universidad de Guadalajara de México. Agradezco al profesor Francisco Ortega el extenderme la invitación a participar. Igualmente, agradezco a las profesoras Elysa Cárdenas Ayala, coordinadora del Grupo Religión y Política de IberConceptos, y a Rosa Vesta López Taylor, profesora de la Universidad de Guadalajara, con quien he compartido varias de estas reflexiones.

(cC) BY-NC-SA Esta obra está publicada bajo la licencia CC Reconocimiento- No Comercial - Compartir Igual 4.0 


\section{Resumen}

El presente artículo propone algunas reflexiones que problematizan las enunciaciones de la herejía y el cisma, bien por las autoridades eclesiásticas, bien por las autoridades civiles republicanas desde la ciudad de Bogotá - al mismo tiempo sede tanto del poder temporal como del poder espiritual - entre los años 1819 y 1826 . Al respecto, se indaga por cuáles son los problemas que reflejan dichas enunciaciones, máxime cuando herejía y cisma refieren a situaciones límite en el seno de la historia del cristianismo. Desde los conflictos entre clérigos por desviaciones de la ortodoxia católica, pasando por el proceso de censura de libros por parte del sector eclesiástico, se encuentra una ambivalencia de la herejía entre los contornos de lo religioso y lo político, por cuanto este último la resignifica en su experiencia límite como cisma, erigiéndola como imposibilidad de conciliación de las diferencias en el seno de la naciente república.

Palabras clave: Herejía, cisma, censura, orden político, clero.

\section{Abstract}

This papper propouses some reflexions that aim to problemaize the enunciations of the heresy and schism, either by the ecclesiastical authorities or by the republican civil authorities in the capital of Bogota - at the same time the place of temporal power as well as spiritual power - between the years 1819 to 1826 . In this regard, it investigate which are the problems that these statements reflect, especially when both refer to extreme situations within the history of Christianity. From the conflicts between clerics for deviations from Catholic orthodoxy, through the process of censorship of books by the ecclesiastical sector, there is an ambivalence of the heresy between the religious and political contours, since the latter resignifies it in his limit experience as a schism, erecting it as an impossibility of reconciling differences within the nascent republic.

Key words: Heresy, schism, censorship, political order, clergy. 


\section{Nombrando las desviaciones para fijar adhesiones. Una interpretación de las circulaciones de la herejía y de la condena a los herejes desde la ciudad de Bogotá, $1819-1826$}

\section{Introducción}

A partir de las posibilidades abiertas con la invasión de las tropas francesas a España en 1808, (destacando la truncada consumación de las independencias de los antiguos reinos de Indias bajo control de la monarquía confesional) es relevante señalar que, como corolario no menos significativo, las relaciones entre religión, política, Iglesia, Estado y sociedad se vieron avocadas a reconfiguraciones, si bien no exentas de conflictos, pero sí en un marco político desconocido para los actores en el juego del orden político republicano. Aunque las voces a favor de cambios en estos entramados se manifestaban con mayor ahínco desde mediados del siglo XVIII en ambos lados del Atlántico ${ }^{2}$, desde aquel año se puede establecer un nuevo punto de definiciones de las relaciones, por cuanto, como recuerda Annick Lempérière, "la religión de Estado se ha transformado en un objeto de debate político, lo que nunca se hubiera podido imaginar bajo la monarquía católica”3.

2 Para una lectura de conjunto de algunos países de Europa, se trae a colación el estudio del

historiador chino Ronnie Po-Chia Hsia, El mundo de la renovación católica (Madrid: Ediciones Akal, 2010). En complemento, y según las apreciaciones de Brian Connaughton para el caso del Virreinato de Nueva España, pero que pueden extenderse a otros dominios coloniales, tales demandas de cambios en las relaciones entre religión y política abarcaban puntos como el número y composición de las diócesis, la delimitación de los alcances del poder episcopal, las relaciones con la Santa Sede o las reformas de costumbres y la depuración de las prácticas de fe. Ver Brian Connaughton, "El constitucionalismo político-religioso. La Constitución de Cádiz y sus primeras manifestaciones en el Bajío mexicano y zonas aledañas”, Relaciones. Estudios de Historia y Sociedad 37, n.. 147 (2016): 86-89, http://www.scielo.org.mx/scielo. php?script=sci_arttext\&pid=S0185-39292016000300085\&lng=es\&nrm=iso

3 Annick Lempérière, “¿Nación moderna o repúblicabarroca? México 1823-1857”, en Imaginar la nación. Cuadernos de Historia Latinoamericana n. $\underline{2}$, Revue de Ahila, coords. François-Xavier Guerra y Mónica Quijada (Münster-Hambourg: LIT Verlag, 1994), 143. 
De esto último dan cuenta los vaivenes por los cuales atravesó la adhesión a la imagen del rey español Fernando VII y el orden por él encarnado y regulado en el Virreinato de la Nueva Granada, en el cual la religión católica (tanto en su institucionalización como en plano de las creencias) se conjuraba ante sus vasallos para legitimar la fuente del poder político como una concesión divina. Entre 1808 y 1819, la figura del monarca estaría sujeta a definiciones que, al pasar de los años, irán otorgando veracidad al despotismo y la tiranía contra los cuales se afianzaban los discursos de los republicanos criollos. Si el "entusiasmo lealista" de los primeros años terminó al final con la "mundanización de la potencia regia”, muy a pesar de los esfuerzos del Ejército Expedicionario de Tierra Firme, comandado por el general Pablo Morillo en su intención de imponer el retorno de grupos sociales a la lealtad por medio de la violencia ${ }^{4}$, no menos interesante resulta el desplazamiento de los argumentos que se esgrimían desde la cátedra de san Pedro por parte del clero, alegando a su feligresía la adhesión al monarca, pues, en consonancia con el halo de sacralidad del que supuestamente estaba imbuido, la tríada Dios, Patria y Rey no se dibujaba como tres elementos diferenciados en la cotidianidad. Por esto mismo, los calificativos de herejes e impíos recayeron sobre personas e ideas (la soberanía del pueblo, por ejemplo) que contrariaban algunos de los fundamentos de la comunidad política colonial; elaboración que en escritos de algunos representantes del clero se vinculaba a las manifestaciones concretas del mal y del fin de los tiempos que anunciaban Napoleón Bonaparte y la Revolución francesa ${ }^{5}$, lo cual serviría desde entonces a una parte de los pensadores católicos de las nacientes repúblicas para argumentar la supuesta pérdida del papel protagónico de la religión católica en la sociedad que pregonaban agentes imbuidos en las ideas de "filósofos libertinos", como advertía el religioso agustino fray Diego Francisco Padilla (1754-1829), reconocido defensor de la libertad y la causa patriótica, en su periódico Aviso al Público entre 1810 y $1811^{6}$.

4 Isidro Vanegas Useche, "El rey ante el tribunal de la revolución: Nueva Granada 1808-1819”, Historia y Sociedad, n. 31 (2016): 17-47, https://doi.org/10.15446/hys.n31.55457

5 Esta propuesta interpretativa de la tríada Dios, Patria y Rey es retomada de José David Cortés Guerrero, "Los sermones en la Independencia colombiana. De la defensa del monarca español a la defensa de la república”, en Independencia: historia diversa, ed. Bernardo Tovar Zambrano (Bogotá: Universidad Nacional de Colombia 2012), 109-149.

6 Citado por Iván Darío Toro Jaramillo, "Clero insurgente y clero realista en la Revolución colombiana de la Independencia”, Anuario de Historia de la Iglesia17 (2008): 127-128, https:// revistas.unav. edu/index.php/anuario-de-historia-iglesia/article/view/9974 
Ahora bien, los argumentos condenatorios de los rebeldes criollos por parte de miembros del clero indiano, desde 1808 en adelante, recurrieron igualmente a los calificativos de herejes y herejía en otras latitudes del continente americano con los objetivos de desmeritar, perseguir y condenar las adhesiones a las causas de la república criolla de los hasta entonces vasallos de la monarquía. Sabido es que el sacerdote Miguel Hidalgo y Costilla (1753-1811) jugó un papel relevante en la justificación de la independencia contra las autoridades españolas en el Virreinato de Nueva España (México). Ante la pregunta de "quién lo había hecho juez competente de la defensa del reino, dijo que era el derecho que tiene todo ciudadano, cuando cree la patria en riesgo de perderse". Una vez capturado, fue conducido al Tribunal de la Santa Inquisición (en donde con anterioridad se le había abierto proceso, entre 1800 hasta 1809 , a causa de la lectura de libros prohibidos que contenían máximas heréticas) esta vez para condenarlo por "sospechoso de ateísmo y materialismo... sectario de la libertad francesa ... libertino, sedicioso, cismático”, con lo cual se justificaba el traslado de su proceso al tribunal civil, que toma por medida su fusilamiento ${ }^{7}$.

Otros ejemplos se pueden encontrar con algunos hechos que tuvieron lugar en el Virreinato del Río de la Plata. Si bien durante los intentos de las invasiones de tropas del Imperio británico en 1806 y luego en 1807 no faltaron voces de alarma, aunque muy tenues, sobre el miedo a los herejes, haciendo referencia a "los otros cristianos", los protestantes, lo relevante es que las menciones de herejía cobran mayor dinamismo durante los años de la guerra por la independencia, ubicándose su uso en el seno de la religión católica y de las entidades a ella adscritas, mas no en contra de los protestantes, quienes no configuraban un grupo población significativo a inicios del siglo XIX. En este sentido, y continuando con los argumentos de Nancy Calvo, "la división de la sociedad en tiempos de la independencia convierte la intolerancia en un problema entre católicos que se disputan, también, el capital religioso", por lo cual los improperios de fanáticos, supersticiosos, herejes o libertinos

7 Carlos Herrejón Peredo, "Hidalgo: la justificación de la insurgencia”, Relaciones. Estudios de Historia y Sociedad IV, n.o 13 (invierno 1983): 31-53, https://www.col mich.edu.mx/ relaciones25/files/revistas/013/CarlosHerrejon.pdf Con una lectura que complementa las ideas religiosas disponibles desde el siglo XVIII en Nueva España y que tuvieron eco en una parte del clero, ver Ana Carolina Ibarra, “'La justicia de la causa': razón y retórica del clero insurgente de la Nueva España”, Anuario de Historia de la Iglesia 17 (2008), 63-80, https:// revistas.unav.edu/index.php/anuario-de-historia-iglesia/article/view/9973 
estuvieron orientados a denostar la participación en uno u otro bando en contienda 8 .

Con las victorias de las tropas patriotas en los campos de Boyacá en 1819 se abre paso, en el espesor de las inestabilidades sociales, la construcción de la comunidad política bajo principios republicanos, sumada a la puesta en marcha del proyecto político de la República de Colombia ${ }^{9}$. En consonancia, el presente artículo tiene por objetivo problematizar las circulaciones y usos de la religión católica (creencias, discursos e institución) desde la ciudad de Bogotá, al mismo tiempo ciudad capital del poder político republicano y de la Iglesia institucional ${ }^{10}$, matizando las siguientes reflexiones a partir de las enunciaciones de la herejía y de las condenas al hereje como lugares sobre los cuales vuelven los diferentes actores a partir de las situaciones descritas hasta 1826, año en el cual disminuye el movimiento militar, mientras la legitimidad del

8 Punto interesante es que la historiadora muestra el paralelo en la construcción de las identidades religiosas católicas y protestantes que tienen lugar entre 1813 hasta 1825 cuando se logra la aprobación formal de la libertad de conciencia y la tolerancia de cultos para los residentes británicos en Buenos Aires - que configuran el campo religioso de la posindependencia. Ver Nancy Calvo, “Los unos y los otros. Católicos, herejes, protestantes, extranjeros. Alcances de la tolerancia religiosa en las primeras décadas del siglo XIX", Аnuario IEHS, n. 21 (2006): 13-35, y http://anuarioiehs.unicen.edu.ar/resumenes/2006/1\%20 Los\%20unos\%20y\%20los\%20otros.\%20Católicos,\%20herejes,\%20protestantes, $\% 20$ extranjeros.\%20Alcances\%20de\%20la\%20tolerancia\%20religiosa\%20en\%20Buenos\%20 Aires\%20durante\%20las\%20primeras\%20décadas\%20del\%20siglo\%20XIX.html

9 Con la promulgación de la Ley Fundamental del Congreso de Angostura en diciembre de 1819 se crea la República de Colombia, integrada por los territorios correspondientes a las entidades administrativas hasta hace poco denominadas como Capitanía General de Venezuela y el Virreinato de la Nueva Granada. Posteriormente se agregaría la Real Audiencia de Quito. Con la promulgación de la Constitución Política de Cúcuta en 1821 se formaliza la República de Colombia, y la denominación del departamento de Cundinamarca corresponde a los territorios adeptos a la independencia del antiguo Virreinato de la Nueva Granada. Este proyecto político llega a su fin en 1832 con la separación de Ecuador y Venezuela y su proclamación como repúblicas autónomas.

${ }^{10}$ Recordar en este punto que la arquidiócesis de Bogotá fue creada en 1563 y bajo su administración quedaron regladas las diócesis de Santa Marta y de Cartagena, erigidas en 1534; la diócesis de Popayán, fundada en 1546; la diócesis de Antioquia, erigida en 1804. Esta administración del episcopado a inicios del siglo XIX fue seguida de la erección de otras diócesis durante el siglo XIX. Ver José David Cortés Guerrero, La batalla de los siglos. Estado, Iglesia y religión en el siglo XIX. De la independencia a la Regeneración (Bogotá: Universidad Nacional de Colombia, 2016), 16, nota a pie de página número 6. 
orden constitucional y del gobierno vigente son cuestionadas al manifestarse "la tensión entre la soberanía unitaria y abstracta del pueblo, representada en el Congreso, y la soberanía compuesta de los pueblos" ${ }^{\text {"11 }}$. Las preguntas generales con las cuales se pretende hilar las siguientes reflexiones son las siguientes: ¿cómo comprender los usos y significados por parte de la autoridad política republicana de las enunciaciones de la herejía y del hereje en sus intenciones de calificar, condenar y persuadir las adhesiones al nuevo estado de cosas? Pero, en un plano diferente, ¿cómo comprender la recomposición de la religión católica y de la Iglesia institucional a partir de la recurrencia a dichas enunciaciones? Si bien en términos analíticos han de elaborarse en la escritura como separados, ambos planos (para lo religioso y para lo político) invitan a pensar un problema mucho más complejo y aún pendiente por resolver en la historia actual de nuestro país: la gestión política de las diferencias.

Las situaciones abordadas en el presente artículo, cuando no hagan referencia a otras investigaciones, dan cuenta de las consultas de fuentes impresas que reposan en la Biblioteca Nacional de Colombia, así como de fuentes manuscritas (de las cuales se mantiene la ortografía original al momento de su transcripción) bien en custodia del Archivo General de la Nación, bien del Archivo Histórico Cipriano Rodríguez Santa María, administrado por la Universidad de la Sabana.

\section{Una norma antiherética en aras del consenso político}

La justificación para elegir el año de 1819 como punto de partida para las siguientes reflexiones se debe a las medidas emitidas en la orden del 2 de diciembre, por la cual el vicepresidente Francisco de Paula Santander, previa concertación con el prebendado de la catedral metropolitana de Santafé, Nicolás Cuervo, obligaba a los párrocos de la arquidiócesis de Bogotá a escribir y leer en sus púlpitos los "tres sermones de Patria", es decir, que versaran sobre los temas de la Independencia, la Constitución Política y las victorias militares de las tropas patriotas ${ }^{12}$. La producción de estas piezas homiléticas, entre 1819 y 1820 , no es nada desdeñable, por cuanto las estimaciones de los

${ }^{11}$ María Teresa Calderón y Clément Thibaud, “Un Gobierno vacilante, 1826-1831”, Capítulo 7 en La majestad de los pueblos en la Nueva Granaday Venezuela (1780-1832) (Bogotá: Universidad Externado de Colombia, 2010), 195-196. Énfasis en el original.

${ }^{12}$ Armando Martínez Garnica, “La ambición política restringida: la República de Colombia”, Capítulo 2 en Historia de la República de Colombia, 1819-1831 (Bogotá: Universidad del Rosario, 2019), 116-118. 
investigadores daban cuenta de más de un centenar hasta hace pocos años ${ }^{13}$, aunque recientemente, mediante el acuerdo editorial entre el Archivo General de la Nación y la Academia Colombiana de Historia se ha reunido un corpus documental de 199 sermones gracias al proyecto coordinado por Armando Martínez Garnica ${ }^{14}$.

La orden fijaba las dos temáticas sobre las cuales debían ahondar los miembros del clero que se hacían denominar adeptos a la comunidad política republicana en la argumentación y la comunicación de las piezas sermonarias:

\section{1.‥Que el sistema de independencia es conforme a la doctrina de Jesucristo} $\mathrm{y}$, por consiguiente, los que lo siguen no son herejes.

2.‥ Que si la Nueva Granada por desgracia, y por pecados de sus habitantes, fuese subyugada nuevamente por los españoles, sufrirá males mayores que los que ha padecido en los tres años pasados, que al efeto se referirán ${ }^{15}$.

${ }^{13}$ Por ejemplo, las historiadoras Margarita Garrido y Viviana Arce Escobar realizaron sus interpretaciones de la serie "Oratoria Sagrada” de la Colección Ortega Ricaurte, que se explica en la siguiente nota al pie. Mientras Margarita se detiene en veintiocho de estas piezas, Viviana considera una aproximación inicial de setenta sermones consecuentes con esta medida, que en las estimaciones de la historiadora, entre 1819 y 1820 se produjeron más. Ver Margarita Garrido, "Los sermones patrióticos y el nuevo orden en Colombia, 1819-1820”, Boletín de Historia y Antioüedades XCI, n. 826 (2004): 461-483; Viviana Arce Escobar, “La Biblia como fuente de reflexión política en los sermones neogranadinos, 1808-1821”, Revista CS, n. 9 (enero 2012): 277-278, https://www.icesi.edu.co/revistas/index.php/revista_cs/article/ view/1223 A su vez, las estimaciones de Armando Martínez Garnica hablan de una colección de 112 sermones. Ver “La ambición política restringida: la República de Colombia”, 117.

${ }^{14}$ Este corpus corresponde, como explicita Luis Horario López Domínguez, "de dos fondos del Archivo General de la Nación, AGN: 1. Un primer segmento de mayor volumen, corresponde a Sección República, Fondo “Libros Manuscritos y Leyes Originales de la República”, tomos XII y XIII del AGN. 2. Un segundo grupo de sermones proviene de la Serie "Oratoria Sagrada", la cual hace parte de 120 secciones de diversa temática, conocido como Colección Ortega Ricaurte", la que fue resultado de la intervención selectiva realizada en el siglo XX por el académico Enrique Ortega Ricaurte, director del Archivo Nacional de Colombia, hoy Archivo General de la Nación, AGN. 3. Por último se adicionó un sermón procedente del Fondo Pineda 309, 103 de la Bíblica Nacional de Colombia. Son estas las fuentes documentales de la publicación, y al final de cada sermón se registra el fondo correspondiente de procedencia del documento", Luis Horario López Domínguez, "Nota Metodológica Editorial” en Sermones patrióticos en el comienzo de la República de Colombia, 1819-1820, Tomo I (Bogotá: Academia Colombia de Historia / Archivo General de la Nación, 2020), XXVIII-XXIX.

15 “Orden del vicepresidente Francisco de Paula Santander para que todos los párrocos del departamento de Cundinamarca exhorten a sus feligresías sobre la conformidad de la In- 
Al respecto, aunque seagrosso modo, la historiografía ha vuelto sobre algunas implicaciones ante aquellas necesidades de claridad que se pronunciaran desde el púlpito, indicando que, por ejemplo, el conjunto de los sermones producidos durante 1819 y 1820 expresan "las ideas en este tiempo fuerte en que un cambio en la representación del orden era indispensable para afianzar el nuevo sistema”. Bajo esta premisa, Margarita Garrido llama la atención sobre los elementos en juego, tales como el tránsito de las identidades sociopolíticas del vasallo hacia las del ciudadano, los sentidos de pertenencia al nuevo orden de cosas o la mediación de la oratoria sagrada para "ayudar a dilucidar las ideas en el conflicto de significados que la Independencia había producido entre sus feligreses" ${ }^{16}$. En complemento, bajo el objetivo de interpretar los usos de los textos bíblicos en la confección de algunas piezas sermonarias (con una mirada que no recae exclusivamente en la orden del 2 de diciembre), los estudios de Viviana Arce Escobar muestran los usos alegóricos, en mayor medida, de los libros del Antiguo Testamento y de las profecías allí expresadas que auguraban los nuevos designios de la Providencia, sobre todo como renovación de la alianza entre Dios y el pueblo escogido. En complemento, anota que "la idea de un Dios temeroso y a la vez amoroso sirvió para calmar los ánimos de los fieles angustiados"17.

Por su parte, Fernando Muñozrecuerda las condenas que el papa Pío VII en $1816^{18}$ había sentenciado contra los rebeldes americanos, argumento del cual

dependencia con la doctrina de Jesucristo" (Santafé, 2 de diciembre de 1819), en Sermones patrióticos en el comienzo de la República de Colombia, 1819-1820. Tomo I, coord. Luis Horacio López Domínguez (Bogotá: Academia Colombia de Historia / Archivo General de la Nación, 2020), CI. En complemento de esta orden, desde el cuartel general de Santafé, el 4 de diciembre de 1819 , se ordenaba a jefes políticos y militares que programaran rogativas y misas, las cuales debían estar acompañadas de las imágenes de los patronos. Dichas celebraciones debían demandar la protección del orden celestial en pro de la República, así como de las tropas que se disponían a marchar hacia regiones como la costa caribe o las provincias de Popayán y Pasto, aún bajo control del ejército español.

${ }^{16}$ Punto importante es que el sermón es definido como "el más formidable medio de formar la opinión en la sociedad”. Garrido, “Los sermones patrióticos”, 463-467. Énfasis en el original.

17 Viviana Arce Escobar, "El púlpito entre el temor y la esperanza: ideas de castigo divino y misericordia de Dios en la oratoria sagrada neogranadina, 1808-1820", Anuario de Historia Regional y de las Fronteras 17, n. 1 (2012): 102-103, DOI: 10.18273/revanu. En complemento, ver el artículo citado en nota al pie 13. (revisar esta dirección DOI pues parece genérica de muchos otros artículos de diversos temas).

18 Se trata del breve Etsi longissimo terrarum ac marium intervallo dissti a nobis sitis, "aunque estemos separados por un dilatadísimo espacio de mar y tierra”, emitido en enero de 1816. 
hicieron eco los prelados realistas para la defensa del rey español, calificando como herejes a todos aquellos que contrariaran el andamiaje monárquico. La tarea encomendada al clero adepto (por convicción o por conveniencia) a la Independencia consistía, entonces, en "redimensionar el concepto de herejía [...] a la luz de la razón, de la teología y, sobre todo, de la Sagrada Escritura". Con una concepción estrecha de herejía, tomada como simple desviación de la fe, el historiador muestra algunos de los argumentos esgrimidos en el sermón del cura de Funza orientados a mostrar la tensión entre libertad y sujeción al despotismo ${ }^{19}$.

Compartiendo los puntos abordados con anterioridad (que no agotan los estudios al respecto) Armando Martínez Garnica llama la atención sobre el mérito del vicepresidente Francisco de Paula Santander al "entender el valor estratégico del clero en la construcción de la nación colombiana y la utilidad de los sermones patrióticos". En relación con los argumentos propiamente de las piezas sermonarias destaca la recurrencia a la historia del antiguo pueblo judío, la "satanización" de los españoles como punto de no retorno, la lucha contra el dominio monárquico como un "deber moral y una obligación existencial”, entre otros. Por el contrario, se echa de menos una interpretación de los entramados por la enunciación de la herejía, si bien no deja de brindar algunas ideas al respecto. Por ejemplo, comparte la transcripción de la parte del sermón en la cual fray Domingo Gálvez O. P., cura de la parroquia de Nuestra Señora del Rosario de Chocontá, luego de preguntar "Y bien, hermanos míos, ¿qué cosa es herejía?”, responde: “Herejía no es otra cosa que un error voluntario y pertinaz contra la doctrina y verdad de fe católica en aquel que ha recibido la fe" ${ }^{20}$.

De lo dicho hasta el momento queremos destacar dos consecuencias: en primer lugar, la orden de 1819 procuraba fijar sentidos unívocos a las enunciaciones de la herejía, puesto que, sin importar el bando en tiempos de transición entre el vasallaje monárquico y la ciudadanía republicana, lo que estaba ahora en entredicho era la autoridad legítima que condenara el error para asegurar la tranquilidad pública y el bien común. En segundo lugar, con fray Domingo Gálvez se entreven elementos que configuran, a través de la herejía,

19 Fernando Muñoz, "Aproximación al imaginario religioso del periodo independentista", Historia y Espacio 6, n. ${ }^{\circ} 35$ (2010): 186-189, https://historiayespacio.univalle.edu.co/index. $\mathrm{php} /$ historia_y_espacio/article/view/1755/1860

20 Armando Martínez Garnica, "Introducción”, en Sermones patrióticos en el comienzo de la República de Colombia, 1819-1820. Tomo I, coord. Luis Horacio López Domínguez (Bogotá: Academia Colombia de Historia / Archivo General de la Nación, 2020), CXLVII-CLXX. 
la historia del cristianismo en Occidente desde, por lo menos, la Edad Media. El siguiente apartado estará dedicado a ahondar en esto último.

\section{Propuesta historiográfica para interpretar las circulaciones de la herejía y la condena a los herejes de inicios del siglo XIX}

¿Por dónde comenzar? Recordando que la herejía y los herejes fueron calificados como tales antes de la instauración de la institución eclesiástica inquisitorial. Según su etimología del griego antiguo, la herejía designa "elección", que puede surgir como "una curiosidad ávida de penetrar en el misterio; de conseguir, en la oscuridad de su trascendencia, una inteligencia”. Así las cosas, "el acto del hereje se produce en el interior de su fe", bien para apelar a una modificación progresista (re-formatio), bien para demandar un retorno a la pureza primitiva (re-novatio) ${ }^{21}$. Con o sin intención inmediata, el hereje invita a las personas próximas a seguir su iniciativa de contraponer "otras verdades" ante aquellas que han sido establecidas por la "tradición” (teologal, eclesiástica, canónica, etc.), y así encuentra voces cercanas que adhieren para formar juntos "otro medio social, en el que le dan una nueva orientación a la vida espiritual y, frecuentemente, material”22.

Dicha posibilidad de estructurar otro consensus comunitario se había presentado desde los primeros siglos del cristianismo y al respecto san Agustín, en vida obispo de Hipona, establece una propuesta que va a configurar las relaciones entre el poder temporal y la Iglesia institucional desde entonces. Continuando con Jean Séguy, san Agustín, al hacer triunfar para la cristiandad occidental la opinión de que "la Iglesia es una institución de salvación, continuación sacramental de Jesucristo, y la dignidad o indignidad de los ministros no cambia nada" define las relaciones entre la Iglesia y el Estado (conceptos usados por el sociólogo francés) durante siglos al establecer que "el emperador cristiano, Constantino fue el primero (306-337), puede y debe forzar al hereje a volver a la verdad: compelle intrare" ${ }^{23}$.

${ }^{21}$ Marie-Dominique Chenu, “Ortodoxia y herejía. El punto de vista del teólogo”, en Herejías y sociedades en la Europa preindustrial (siglos XI-XVIII), comp. Jacques Le Goff (Madrid: Siglo Veintiuno, 1987), 1-5.

22 Diana Luz Ceballos Gómez, "Política, heterodoxia e Inquisición”, Historia y Sociedad, n. 22 (2012): 69, https://revistas.unal.edu.co/index.php/hisysoc/article/view/32322

23 Jean Séguy, "La religiosidad no conformista de Occidente", IV en Las religiones constituidas en Occidente y sus contracorrientes Volumen II, dir. Henri-Charles Puech (Madrid: Siglo XXI Editores, 1981), 221. Énfasis en el original. 
Hasta aquí se han mencionado algunas características generales de la herejía. Pero, en aras de comprender los sentidos de las enunciaciones de la herejía conviene ahora "penetrar la lógica que articula las distintas categorías [e ideas] que la definen como tal”, retomando aquí las sugerentes hipótesis de investigación de Constanza Cavallero ${ }^{24}$. Al volver sobre la historia de la herejía en la Edad Media es porque, en primer lugar, a las dos categorías con las cuales se nombraban las disensiones religiosas cristianas se suma una definición canónica, citada recurrentemente por la historiografía, que perdura latente hasta nuestros días. El primer elemento habla del carácter intelectivo (falsa credulitas), es decir, de la existencia de una opinión errónea respecto de algún artículo de la fe cristiana. El segundo da cuenta del carácter volitivo (pertinax defensio), es decir, la necesidad imperiosa de que dicha opinión equivocada sea sostenida con pertinacia. Una y otra categoría se conjugan en las reflexiones de los religiosos Pedro el Venerable, abad de Cluny, y el franciscano Roberto Grosseteste, quienes en el siglo XIII definen la herejía como "una opinión escogida por la percepción humana, contraria a la Sagrada Escritura, públicamente declarada y obstinadamente defendida" ${ }^{25}$.

De la anterior definición no solo queda claro que una persona creyente no puede considerarse a sí misma como herética en la interioridad de su corazón. Esto ayuda a matizar, como tercer elemento, a la separación (divisio) de un todo antes unido. Por ejemplo, en las concepciones de la Edad Media los teólogos condenan el impulso de la voluntad subjetiva en contrariar la “voluntad celeste, trascendente e inapelable, interpretada históricamente por los vicarios terrenales de la divinidad"26. Este monopolio de la interpretación es

${ }^{24}$ Constanza Cavallero, Los enemigos del fin del mundo. Judíos, herejes y demonios en el Fortalitium fidei de Alonso de Espina (Castilla, siglo XV) (Buenos Aires: Miño y Dávila, 2016), 214. Esta publicación es el resultado de su tesis doctoral destinada a analizar los elementos constitutivos del campo semántico de la herejía tras las producciones discursivas de un "nuevo" sujeto herético en los escritos del fraile franciscano Alonso de Espina durante los tiempos de la primera revuelta anticonversa de los reinos hispanos en 1449 . Su obra más conocida, el Fortalitium fidei (circa 1460), recurre a nuevos usos argumentativos de nociones y conceptos preexistentes de la Edad Media sobre los heresiarcas en el seno de la sociedad cristiana occidental para argumentar a favor de la existencia de los "herejes ocultos" (iudei occulti), refiriéndose con ello a la "herejía judaizante" y el debate sobre la "cuestión conversa".

${ }^{25}$ Constanza Cavallero, "La temporalidad del lenguaje de la herejía. El caso de la construcción de la herejía judaizante en el ocaso de la Edad Media”, Medievalismo, n.ํ22 (2012): 14-15, https://revistas.um.es/medievalismo/article/view/164311

${ }^{26}$ Cavallero, "La temporalidad, 15. 
tan solo uno de los efectos más sobresalientes del binomio ecclesia-veritas, eje articulador del campo semántico de la herejía. En primer lugar, porque la divisio se establece respecto de una Iglesia institucionalizada, la cual, al mismo tiempo que declara la existencia del error y condena al hereje, se reclama como la única depositaria de la verdad en su jerarquía, además de guardiana de la tradición. En este sentido, los pontificados de Inocencio III y Bonifacio VIII engloban las pretensiones de la reforma eclesiástica de los siglos XI-XIII en hacer creer que la pertenencia a la Iglesia no solo era un imperativo para la salvación de las almas, sino que, más importante aún, se debía asumir la obediencia al papa y sus delegados.

Para lograr la aceptación de estas disposiciones, la alta jerarquía asoció la herejía con el crimen de lesa majestad (crimen laesae magestatis), introduciéndose un cambio semántico de honda importancia. En primer lugar, porque "la ofensa herética quedaba claramente ligada no sólo a disensiones en materia de fe sino también a toda rebeldía que amenazara con menoscabar el poder de la jerarquía de la Iglesia, su dominium universal" 27 . Ante la maleabilidad de establecer otros consensos religiosos entre la comunidad de fieles y la solución agustiniana de obligar al retorno de las disidencias a la unidad sociorreligiosa, se erige la constitución de la "Inquisición Papal" del siglo XIII. Fundación que comprueba la anuencia de las autoridades eclesiásticas y laicas para reprimir y corregir cualquier grupo social que lesionara dicha majestad real, una invención normativa producto del retorno del derecho romano a los contornos eclesiásticos. Como consecuencia, la definición de la herejía como delito contrario al bien común y a la sociedad quedaba establecida desde entonces ${ }^{28}$.

Ahora bien, la asociación de la veritas con la jerarquía eclesial sufrirá un trastorno durante el siglo XVI en la Europa cristiana con mayores repercusiones que en siglos anteriores, puesto que durante este tiempo confluyen no solo la constitución de una herejía en otras Iglesias (con Lutero y Calvino como símbolos destacados), sino que, ante tal reto, el mundo católico sufre profundas renovaciones. Así, mientras una de las esperanzas afincadas por el Concilio de Trento es hacer del obispo un "héroe episcopal", con el paradigma de Carlos Borromeo y su intención "de crear un cuerpo, distinto de los otros, cuyas partes

${ }^{27}$ Cavallero, 17.

${ }^{28}$ Esta es una muy breve síntesis de las investigaciones de la historiadora Diana Luz Ceballos Gómez, tanto en su artículo "Política, heterodoxia e Inquisición”, citado anteriormente, como en su libro Hechicería, brujería e Inquisición en el Nuevo Reino de Granada. Un duelo de imaginarios (Bogotá: Editorial Universidad Nacional de Colombia, 1994). 
se mantengan orgánicamente y obedezcan todas a una sola cabeza” ${ }^{29}$, de forma gradual los príncipes, desde las guerras civiles de religión, comienzan a fracturar el monopolio eclesiástico de las prácticas y discursos de la salvación eterna que antes legitimaban a la institución religiosa, pues ahora la expectativa de tal futuro se busca hacer recaer en el monarca, con lo cual la herejía sufre una mutación de hondas significaciones: "[desde entonces] ya no hay herejía en la religión, existe en el Estado" ${ }^{30}$.

En complemento, para contribuir a la compresión de las enunciaciones de la herejía durante 1819-1826, es importante destacar, por lo pronto, un último elemento, esta vez resultado de la ampliación del "poder de atar y desatar conciencias" que la Iglesia institucional católica pone en marcha desde el Concilio de Trento para modelar al sujeto creyente. Se habla en este punto de la inquisición, ligada al fuero externo, y de la confesión, ligada al fuero interno, dos instrumentos de intervención sobre las conciencias, que si bien habían sido definidos durante los siglos XI-XIII, se pondrán en escena para evitar a toda costa la mutación de las disensiones en una contrainstitución. Desde entonces se buscaba emparentar "dos sistemas de control, dos maneras de excluir o admitir en la comunidad cristiana”, que, al mismo tiempo que individualizaban los comportamientos para "situa[r] cualquier asomo de disensión consciente [...] alentaba[n] todo un entramado de pecados de palabra en aras de descubrir posibles cómplices y redes ocultas"31.

Inquisición y confesión, sumadas a las categorías o elementos constitutivos de la herejía hablan de una intención mancomunada entre las autoridades religiosas y civiles por evitar cualquier viso de ruptura, pues la presencia de los herejes y de las proposiciones por ellos defendidas son un cuestionamiento directo a las verdades, así como a las adhesiones por ellas sustentadas, que soportan las relaciones de poder. Sin desconocer el argumento de Dios como fuente de la sociedad, ahora, en tiempos de la República, se busca lograr el reconocimiento del nuevo estado de cosas, lo cual obliga a resignificar los entramados de relaciones entre religión y política que hasta hace muy poco se

${ }^{29}$ Michel de Certeau, “Carlos Borromeo (1538-1584)”, 5 en El lugar del otro. Historia religiosa y mística (Buenos Aires: Katz, 2007), 130.

${ }^{30}$ Reinhart Koselleck, "Futuro pasado del comienzo de la modernidad”, I en Futuro pasado. Para una semántica de los tiempos históricos (Barcelona: Paidós, 1993), 25-29.

31 Adriano Prosperi, "El inquisidor como confesor", Stvdia Historica. Historia Moderna XIII (1995): especialmente 61 y 85, https:/gredos.usal.es/bitstream/handle/10366/70045/ El_inquisidor_como_profesor.pdf?Sequence=1 
tenían por ciertos. En este sentido, las preguntas por hacer son las siguientes: ¿quién asumirá desde ahora el cuidado de la verdad y de la condena del error? Pero, sobre todo, ¿a qué precio?

\section{Apropiaciones y circulaciones de la herejía para condenar las creencias no conformistas}

Una vez establecida de manera general la problemática, se extienden algunos de los presupuestos historiográficos que han de orientar la escritura. El primero de ellos invita a no agotar la religión en la institución eclesiástica. En los diferentes conflictos entre la Iglesia y el Estado a lo largo del siglo XIX (para Colombia como para América Latina) salen a relucir una y otra vez los papeles que deben desempeñar la religión y la institución eclesiástica en el orden político republicano, sin desconocer que lo religioso se caracteriza por impregnar de formas permanentes todo lo social, "sin distingos entre lo público y lo privado" 32 . Por tanto, ni las creencias religiosas ni la religiosidad deberían asociarse inequívocamente al dominio eclesiástico, si bien este último configura muchas de las maneras y de las limitaciones individuales y sociales de practicar la fe. Agregar, además, la siguiente advertencia: "la Iglesia no ejercía en ninguna sociedad de Antiguo Régimen el pleno control sobre las conciencias"33.

Una segunda equivalencia reevaluada tiene que ver con el uso acrítico de los conceptos de Iglesia y Estado, por cuanto se toman como dos entidades constituidas inequívocamente, desconociendo no solola relación entre el poder temporal y espiritual en el marco del "régimen de cristiandad" que configuró la monarquía hispánica durante tres siglos, sino que, además, desdibuja el carácter polisémico de ambos actores institucionales en las sociedades de Antiguo Régimen. Siguiendo con el argumento del Roberto Di Stefano:

Un esquema binario como el de Iglesia-Estado sería extraño para nuestros ancestros, que distinguían entre espiritual - la religión en el fuero interno-y religioso o eclesiástico - la religión en el fuero externo-: mientras lo meramente espiritual era por lo general privativo del estado eclesiástico

32 José David Cortés Guerrero, La batalla de los siglos. Estado, Iglesia y religión en el siglo XIX. De la independencia a la Regeneración (Bogotá: Universidad Nacional de Colombia, 2016), 12.

33 Brian Connaughton, "La nueva historia política y la religiosidad: ¿un anacronismo en la transición?”, Capítulo III en Entre la voz de Dios y el llamado de la patria. Religión, identidady ciudadanía en México, siglo XIX (México: Fondo de Cultura Económica / Universidad Autónoma Metropolitana, 2016), 69-70. 
(el "monopolio sacramental" del clero), lo religioso o eclesiástico competía a ambas jurisdicciones ${ }^{34}$.

Si la Iglesia no era en las sociedades bajo dominio español una institución homogénea, diferenciada y regulada por una normativa administrativa (tal y como se nos presenta hoy día), el vuelco para la investigación histórica debe orientarse hacia los "hombres de la Iglesia", indicando con esto, en primer lugar, la intención de comprender la red de relaciones que establecía la institución eclesiástica con los feligreses y las autoridades virreinales ${ }^{35}$. Punto importante porque en el seno de una sociedad estamental que reconocía a los ministros de lo sagrado como mediadores culturales, en lo cotidiano se les tomaba como capaces de erigirse en autoridades sociales, políticas y morales ${ }^{36}$. En complemento, retomar la hipótesis de trabajo que invita a no obviar la movilidad del campo religioso, en tanto "sus límites son flexibles, cuestionados y en disputa permanente por actores estatales, societales, oficialistas o de oposición que, con excepciones, no niegan lo religioso, sino que discuten cuál debe ser su presencia y su accionar simbólico e institucional"37.

Desde mediados del siglo XVIII, en el marco de las reformas borbónicas, los significados y prácticas sociales de las redes de relaciones fueron cambiando, afectando directamente las facultades públicas del clero. Con esta finalidad, la Corona resolvió poner en marcha un conjunto de disposiciones que desfiguraban la alianza entrañable entre el trono y el altar, es decir, una suerte de contrato que había soportado la identificación de la monarquía española como cuerpo místico ${ }^{38}$. Dicha metáfora hacía presente (re-presentaba) la

${ }^{34}$ Roberto Di Stefano, ¿¿De qué hablamos cuando decimos 'Iglesia'? Reflexiones sobre el uso historiográfico de un término polisémico", Ariadna histórica. Lenguajes, conceptos y metáforas, n. 1 (2012): 206, https://www.ehu.eus/ojs/index.php/Ariadna/article/view/6152 Letras cursivas en el original.

${ }^{35}$ Miranda Lida, Dos ciudades y un deán. Biografía de Gregorio Funes, 1749-1829. (Buenos Aires: Eudeba, 2006), 12-13.

${ }^{36}$ Amanda Caicedo Osorio, Construyendo la hegemonía religiosa: los curas como agentes hegemónicos y mediadores socioculturales (diócesis de Popayán, siglo XVIII) (Bogotá: Universidad de los Andes, 2008).

${ }^{37}$ Fortunato Mallimaci, "Catolicismo y liberalismo: las etapas del enfrentamiento por la definición de la modernidad religiosa en América Latina”, en La modernidad religiosa: Europa Latina y América Latina en perspectiva comparada, coord. Jean-Pierre Bastián (México: Fondo de Cultura Económica, 2003), 20.

38 Brian Connaughton, "Transiciones en la cultura político/religiosa mexicana, siglo XVII1860. El aguijón de la economía política”, en Poder civil y catolicismo en México, siglos XVI al 
condición de legitimidad del gobierno del monarca españoly sus representantes en suelo americano, configurando una cultura política sustentada en la teoría teológico-política bajomedieval según la cual la soberanía real era vicaría (delegación) de la soberanía divina, por lo que el gobierno efectivo del rey debía estar orientado en administrar la justicia para proporcionar la paz a los demás cuerpos de la sociedad (entre ellos la Iglesia, entendida como "sociedad perfecta y anterior al Estado") junto con los restantes cuerpos intermedios, como por ejemplo las comunidades indígenas ${ }^{39}$.

Otra serie de medidas estuvieron encaminadas a reducir los beneficios jurisdiccionales y fiscales, y ante las cuales el clero neogranadino no estuvo exento. La expulsión de la Compañía de Jesús en 1767, seguida del destierro de clérigos extranjeros con domicilio en los reinos indianos, así como la serie de penas contra religiosos y sacerdotes que se pronunciaran contra el monarca soberano en 1768, o la Ley de Consolidación de Vales Reales de 1804, que supuso una expropiación de bienes a los cleros secular y regular, dan alguna idea sobre un recambio en las relaciones entre la monarquía y la institución eclesiástica ${ }^{40}$.

Las anteriores disposiciones ayudan a explicar algunas de las razones que motivaron la activa participación de miembros del clero del lado de las tropas patriotas, decisión que les contrajo a muchos de ellos la expulsión del territorio neogranadino por parte del general Morillo a su arribo en 1815, para quien

XIX, Francisco Javier Cervantes Bello, et ál. (México: Benemérita Universidad de Puebla / Universidad Nacional Autónoma de México, 2008), 447-466. En relación con el cuerpo místico para el orden político del Virreinato de la Nueva Granada, María Teresa Calderón y Clément Thibaud identifican acepciones como "sentido místico", "cuerpos morales" u "orden metafísico”. Ver, especialmente, "La reincorporación de la majestad y de la soberanía en los pueblos", Capítulo 2 en La majestad de los pueblos en la Nueva Granaday Venezuela (1780-1832). (Bogotá: Universidad Externado de Colombia, 2010), 57-83.

39 Juan Bosco Amores Carredano, “' Gobernar en justicia'. Realistas y patriotas en Nueva Granada (1810-1816)”, Capítulo VI en Política y religión en la independencia de la América hispana, eds. Josep-Ignasi Saranyana y Juan Bosco Amores Carredano (Madrid: Biblioteca de Autores Cristianos / Universidad de Navarra: 2011), 140-141.

40 Ana María Bidegain, "Los apóstoles de la insurrección y el vicario castrense (1810-1820)", Boletín de Historia y Antigüedades 100, n.․ 856 (2013): 199-204,https://www.academiahistoria. org.co/boletin/index.php/boletin856/article/view/32/37 Tema igualmente abordado por la autora en "La Arquidiócesis en el periodo de las guerras de independencia, 1810-1819", Capítulo 6 en Arquidiócesis de Bogotá, 450 años: miradas sobre su historia, eds. Jaime Alberto Manceras Casas (Pbro.), Carlos Mario Alzate Montes (O. P.) y Fabián Leonardo Benavides Silva (Bogotá: Universidad Santo Tomás y Arquidiócesis de Bogotá, 2015), 167-171. 
no había duda de que los clérigos eran “apóstoles de la insurrección”. Muchos de ellos murieron en el camino hacia Madrid, mientras otros, luego de sortear diferentes percances, lograron regresar a territorio colombiano ${ }^{41}$.

El clérigo Fernando Caycedo y Flórez (1756-1832), reconocido por su papel como rector del Colegio Mayor de Nuestra Señora del Rosario durante el siglo anterior, fue uno de los pocos religiosos que logró retornar al suelo que le vio nacer. Luego de estar recluido en un convento de la ciudad de Sevilla, y en orden a lo dispuesto en el indulto del rey concedido el 19 de julio de 1818, Fernando Caycedo emprende el viaje de regreso en octubre de 1820, llegando a Santafé casi un año después. Una vez instalado, es nombrado vicario capitular del arzobispado en 1823. Años más tarde será consagrado como el primer arzobispo republicano por medio de la bula del papa León XII de 1827, si bien su postulación a tal nombramiento había sido puesta en consideración de la Santa Sede desde el 31 de julio de 1823, gracias a las gestiones del cura patriota de Mérida, Lasso de la Vega, y al secretario enviado por parte del Gobierno de Colombia, el secretario Ignacio Sánchez de Tejada ${ }^{42}$. Una vez de regreso, y en continuidad con su adhesión al orden republicano, puesto que en 1813 había hecho parte del Colegio Electoral y Revisor que proclamó la independencia absoluta de Cundinamarca, no se opuso inicial y abiertamente ante las disposiciones del Gobierno republicano destinadas a lograr el favor del clero para la construcción de la legitimidad al nuevo estado de cosas, si bien sus condiciones de salud no le eran favorables para el cargo.

Interesante aspecto es que, luego de unos meses de haber tomado posesión como provisor de la arquidiócesis, el prelado Caycedo seguirá invitando a la cautela de la predicación de los miembros del clero, tal vez en consonancia con el decreto del 4 de enero de 1822, por medio del cual se establecía la dependencia

${ }^{41}$ Bidegain, "La Arquidiócesis", 177-200.

${ }^{42}$ Josep-Ignasi Saranyana, dir., y Carmen-José Alejos Grau, coord., "La teología de la independencia”, III en Teología en América Latina, Volumen II/2, De las guerras de independencia hasta finales del siglo XIX (1810-1899) (Madrid: Universidad de Navarra / Iberoamericana / Verveut, 2008), 245-249. José Restrepo Posada, "Ilmo. Señor Don Fernando Caycedo y Flórez”, XXXVI en Arquidiócesis de Bogotá. Datos biográficos de sus prelados, Volumen III, 1823-1868 (Bogotá: Academia Colombiana de la Historia, 1963), 50-53. Igualmente, se extraen referencias aportadas por Ana María Bidegain en las dos investigaciones reseñadas en la nota anterior. 
civil del clero colombiano al Gobierno ${ }^{43}$. En edicto de 19 de octubre 1823 el provisor de la arquidiócesis exhorta y advierte lo siguiente:

A todos los sacerdotes de uno y otro clero, que tengan licencia de predicar el santo evanjelio, hacemos saber: que por el supremo poder ejecutivo de la República de Colombia se nos ha requerido para que por nuestra parte se tomen las medidas oportunas á fin de contener el celo indiscreto é imprudente de algunos predicadores, que con sus sermones abusan de su sagrado ministerio profiriendo proposiciones capaces de alarmar á los pueblos sencillos, inocentes y celosos de nuestra santa relijion, turbando la paz y tranquilidad pública con sus indiscretas predicaciones ${ }^{44}$.

No era para menos. Ante la ausencia del máximo jerarca en la arquidiócesis de Bogotá, la cual estuvo bacante entre 1804 y 1828, Fernando Caycedo tuvo que afrontar diferentes apuros durante su administración eclesiástica, suscitados unas veces por las diferentes posiciones del clero ante la indisciplina eclesiástica, o gracias a la posibilidad abierta por ella; como por ejemplo en el caso de la participación de algunos clérigos en la masonería; otras veces por las disposiciones de Roma contrarias al reconocimiento de la soberanía de las nuevas repúblicas americanas, con las consabidas bulas condenatorias de los papas Pío VII y León XII ${ }^{45}$; unas más por la llegada y circulación de

${ }^{43}$ Dicho decreto establecía, entre otras cosas, que cuando se fuesen a proveer los beneficios eclesiásticos, los obispos quedaran obligados a pasar a los respectivos intendentes departamentales las listas de los presbíteros ganadores de las oposiciones, con detalle de sus respectivos servicios prestados a la Iglesia y de los que justifiquen su conducta política. Ver Armando Martínez Garnica, “Introducción”, en Sermones patrióticos en el comienzo de la República de Colombia, 1819-1820, CLIV.

${ }^{44}$ Fernando Caycedo y Flórez, Nos el doctor Fernando Caycedo, y Flores, Arcedeano de esta Santa iglesia metropolitana de Santafpe de Bogotá, Provisor, Vicario Jeneral, y Gobernador de su Arzobispado sede vacante (Santafé: Imprenta de la República por Nicomedes Lara, 1823) s. p.

45 Para una interpretación de conjunto, ver John Lynch, “Independencia. Una revolución pecaminosa”, Capítulo 4 en Dios en el nuevo mundo. Una historia religiosa de América Latina (Barcelona: Crítica, 2012), 139-175. Para la situación particular de Colombia, ver José David Cortés Guerrero, "De la aceptación de la independencia a la separación de las potestades, 1835-1853”, Segunda parte en La batalla de los siglos. Estado, Iglesia y religión en el siglo XIX. De la independencia a la Regeneración (Bogotá: Universidad Nacional de Colombia, 2016), 115-224. En complemento, ver William Elvis Plata Quezada, "El catolicismo liberal (o liberalismo católico) en Colombia decimonónica”, Franciscanum. Revista de las ciencias del espíritu 51 n. 152 (2009): 71-32, https://www.revistas.usb.edu.co/index.php/Franciscanum/article/ view/954/827 
ideas y movimientos religiosos de signos contrarios a la pretendida ortodoxia católica, condensada con la creación de la Sociedad Bíblica o el debate contra el utilitarismo y las obras de Jeremy Bentham; otras tantas por las disposiciones de las autoridades republicanas, con medidas tales como la conversión de los conventos menores en instituciones para la enseñanza ${ }^{46}$, la eliminación de los días de fiestas religiosas, la limitación del fuero jurisdiccional eclesiásticos, la eliminación parcializada del diezmo para ciertos productos agrícolas, la exención del pago de derechos parroquiales a los indígenas, la exclusión de los clérigos del Congreso o la ley de patronato republicano como un derecho soberano ${ }^{47}$.

El anterior caleidoscopio de situaciones a las cuales tuvo que hacer frente el primer arzobispo republicano dimensionan un ambiente complejo de relaciones que debe invitarnos a ir más allá de considerar el supuesto conflicto entre una entidad denominada Estado contra otra entidad denominada Iglesia. Este reduccionismo no ayuda a figurar el entrelazamiento entre religión y política que se muestra más arriba. De manera inicial, basta por preguntarse ¿por qué el provisor Caycedo extendió en su edicto de 1823 las disposiciones de vigilancia al clero por parte de Santander? Pero, al mismo tiempo, ¿qué nos dice esta permanencia de la asociación de la herejía con la independencia?

En aras de proponer unas primeras interpretaciones, se proponen a continuación algunas situaciones que contribuyen a hacer a las ideas de

${ }^{46}$ El estudio de Roger Pita Pico muestra los debates entre el clero y las autoridades republicanas en este sentido, así como los avatares que debieron sortear las comunidades religiosas y el clero afectado por esta medida. Ver Roger Pita Pico, "Conflicto de poderes en torno a las imágenes y alhajas sagradas de los conventos suprimidos en la naciente República de Colombia”, Anuario de Historia de la Iglesia, 26 (2017): 351-379, DOI https://doi. org/10.15581/007.26.351-379

47 David Bushnell, El régimen de Santander en la Nueva Granada (Bogotá: El Áncora, 1985), 249-252. En relación con el debate en torno al patronato republicano, ver José David Cortés Guerrero, "De la aceptación de la independencia a la separación de las potestades, 1835-1853”. El historiador colombiano llama la atención en el escaso tratamiento que ha recibido el tema, máxime cuando configuró las relaciones entre el Estado y la institución eclesiástica hasta mediados de siglo. De paso, hay que recordar que el patronato fue un privilegio otorgado por el papa Julio II a la Corona española en 1508, "consistente en erigir nuevas fundaciones eclesiásticas. En términos prácticos, el Rey se convirtió en un vicario general del Papa con poder para legislar en cuanto al régimen espiritual, la propagación de la fe y el culto divino, y lo que es más, este poder podrá extenderse a las autoridades coloniales en América, por ejemplo, los virreyes". Ver "Las discusiones del patronato en Colombia en el siglo XIX”, Historia Crítica, n. ${ }^{\circ}$ 52: 102, DOI https://doi.org/10.7440/histcrit52.2014.05 
los contornos y de los problemas sociales por los cuales la herejía circula, anunciado al mismo tiempo la permanencia de prácticas del mundo colonial, junto con la reapropiación inusitada de las categorías que en ella confluyen por parte del orden republicano.

\section{Censura de libros y prensa católica}

Con la promulgación de la ley sobre la libertad de imprenta, sancionada el día 17 de septiembre de 1821, se daba desarrollo al artículo 156 de la Constitución Nacional de aquel año. Las intenciones de la ley no solo se dirigían a establecer los usos, abusos y penas de este derecho, sino, sobre todo, a permitir al gobierno republicano el control sobre lo dicho y sobre el autor detrás de las ideas, estableciendo una serie de tipificaciones que determinaban los abusos de acuerdo con su contenido y los castigos correspondientes. Así, si el escrito era contrario a los dogmas de fe, era considerado subversivo; si incitaba a la rebelión, se calificaba como sedicioso; si atacaba la moral, era obsceno; si afectaba la reputación de particulares, se señalaba como libelo infamatorio ${ }^{48}$.

Aspecto llamativo de la ley es la creación de la figura del jurado de prensa ordinario, quien debía reemplazar en algunas de sus facultades al Tribunal del Santo Oficio de la Inquisición de Cartagena, extinto por Ley del 22 de agosto de 1821. La elección de los jurados se realizaba por parte del cabildo del cantón donde hubiera imprenta, destinando para ello los primeros 15 días del mes de enero. En total se escogían 24 ciudadanos, quienes debían cumplir con las cualidades contempladas en los artículos 25 y 26 de la Ley. Para llevar a cabo un juicio contra una publicación, se componía un jurado de acusación, compuesto por siete jurados, el cual tenía la obligación de declarar por unanimidad si el escrito era o no delictivo. En un segundo momento, se establecía la composición de un jurado de calificación, conformado igualmente por siete jueces, y cuya función principal era consentir con el veredicto. Las medidas condenatorias podían incluir prisión, el decomiso de los ejemplares o la censura sobre partes o páginas de las obras ${ }^{49}$.

48 Diana Paola Herrera Arroyave, "La Revolución del cura Botero en Antioquia (Colombia). Una aproximación microhistórica a la disputa por las fuentes del derecho, 1835-1848", Fronteras de la Historia 17, n.o 1 (2012): 142-144, https://revistas.icanh.gov.co/index.php/ $\mathrm{fh} /$ article/view/350

${ }^{49}$ Estas son indicaciones generales sobre el funcionamiento de los jurados de prensa. Una amplia explicación se encuentra en Roger Pita Rico, "La legislación sobre la libertad de imprenta en Colombia en el periodo de Independencia y en la naciente República: convergencias, debates y fluctuaciones", Revista de Estudios Histórico-Jurídicos, n. ${ }^{\circ} 41$ (2019): 341 - 
Según apreciación de David Bushnell, el Gobierno republicano asumía una posición ambigua en materia de censura sobre libros contrarios a la religión, por cuanto prohibía la circulación de publicaciones notoriamente contrarias a la religión al interior del territorio, pero permitía la circulación de libros importados del extranjero, incluidos los más nocivos para la ortodoxia religiosa, situación que no resultó en obstáculo para la censura oficial de escritos como La vida privada de los doce césares o La filosofía de Venus de Aretino, o La teología portátil de Dupuis, gracias a las cercanías entre el vicepresidente Santander y el provisor metropolitano Caycedo ${ }^{50}$.

Si bien la ley de imprenta da cuenta de una intención de incentivar la opinión pública a través de medios impresos, algo que no puede dejarse pasar es la intención de las autoridades republicanas en fijar los contornos de la censura, que en el mundo colonial fue un punto de encuentro entre la monarquía y la Inquisición, si bien ella estuvo bajo la administración directa de la Corona, alejando desde el inicio cualquier intención de autonomía eclesiástica en la materia. Recodar en este punto, aunque sea de paso, el papel que desempeñaba el Consejo Real de Castilla, en consonancia con la promulgación de la Pragmática del año 1502, por la cual se ordenaba la previa licencia real como aprobación para la publicación. Al mismo tiempo, y desde 1551, la Inquisición española comenzaba a implementar las listas de libros prohibidos y expurgados en sus Índices y Catálogos, en sintonía con el Índice tridentino promulgado por Pío IV en 1564. En las colonias americanas, la censura de la Inquisición se practicó de manera directa, tanto en la forma de confiscación, como en el expurgo. De vez en cuando se procedía a su destrucción física. Desde la segunda mitad del siglo XVIII e inicios del siglo XIX, los textos que predominaban eran de autores franceses, tanto en ediciones originales como en traducciones ${ }^{51}$.

366, https://scielo.conicyt.cl/pdf/rehj/n41/0716-5455-rehj-41-00341.pdf En complemento, ver Andrés Alejandro Londoño Tamayo, “Juicios de imprenta en Colombia (1821-1851). El jurado popular y el control de los libelos infamatorios", Anuario Colombiano de Historia Social y de la Cultura 40, n.․1 (2013): 75-112, https://revistas.unal.edu.co/index.php/achsc/ article/view/38764

${ }^{50}$ Bushnell, El régimen de Santander, 260-290. Uno de los decretos en relación con la censura de libros prohibidos es el dado el 9 de octubre de 1823, en el cual se reitera la prohibición del decreto del 13 de mayo de 1822. En relación con esto último, ver Restrepo Posada, "Ilmo. Señor Don Fernando", 28-29.

${ }^{51}$ Para este asunto en particular, vale la pena señalar que la ampliación de los estudios hacia la persuasión y censura efectiva de la lectura de libros prohibidos según las normas del Tribunal de la Inquisición de Cartagena aún está abierta en la historiografía colombiana. 
Y contra autores franceses se proyectaba la censura por fray José Chavarrial, del Convento de Agustinos Calzados de Bogotá, en carta dirigida al provisor del arzobispado con fecha del 14 de 1823.

El libro que V.S. se dignó remitir a mi censura con fecha 14 de Mayo de este año es el Sistema de la naturaleza, escrito por el Varon D. Holbach con notas de Diderot. El solo nombre del Autor, basta para que conocer el merito de tal libro Holbach era un hombre de los mas corrompidos y corruptores. Entre los elogios que tributan sus admiradores, uno es: el haber sido como Sardanapalo entregado a la sensualidad, y como Apicio, á la crapula, hasta hacer el panegirico de su cocinero, y haber buscado el mejor de toda la Francia. Así es que en este libro ataca la revelacion, se burla de la ley de Moyses, y del nuevo Testamento, niega la inmortalidad del alma, aconseja el suicidio, hace la apología del Atheismo, y renueva todos los antiguos errores; en este libro se halan las pestilentes doctrinas de Epicuro, de Lucrecio, de Aristipo, de Hobbés y otros. El no respira sino blasfemias contra la Divinidad, el desprecio mas criminal de las reglas de las costumbres y de las leyes de la sociedad; de suerte que en este solo libro parece que el Ynfierno ha reunido todas sus fuerzas, para transformar la Religiones $^{52}$.

Si todos estos males se identificaban en la obra de un único autor, ¿qué podía esperar la sociedad neogranadina si se permitía la circulación de más obras y más autores, “apóstoles de la religión”" ${ }^{3}$ ? Estos embates conmueven al provisor Fernando Caycedo a dirigir oficio al gobierno republicano, con fecha del 28 de septiembre de 1823, solicitando el auxilio para recoger todos los libros obscenos que atacan a la religión y que circulan por la ciudad en grandes cantidades. Estos libros, que corrompen las costumbres, atacan los dogmas,

Para efectos de la argumentación se retoman algunos datos generales de los estudios de conjunto de Enrique Gacto, "Libros venenosos", Revista de la Inquisición, Intolerancia y Derechos Humanos, n.. 6 (1997): 7-44, https://www.boe.es/biblioteca_juridica/anuarios_derecho/ articulo.php?id=ANU-I-1997-10000700044; Pedro Guibovich Pérez, "La censura de libros”, en Literatura y cultura en el Virreinato del Perú: apropiación y diferencia, vol. 2, coords. Raquel Chang-Rodríguez y Carlos García-Bedoya (Alicante: Biblioteca Virtual Miguel de Cervantes, 2017), 55-82. http://www.cervantesvirtual.com/obra/literatura-y-cultura-en-el-virreinato-del-peru-apropiacion-y-diferencia-volumen-2-849332/

52 Arzobispado de Bogotá, “Comunicación al provisor por los Agustinos Calzados”, 1823. Tomo: 25. Folio 524r, Fondo: República. Sección: Curas y Obispos, Archivo General de la Nación (AGN), Bogotá-Colombia.

${ }^{53}$ Ignacio de Márquez a Fernando Caycedo y Flórez, 1823, Fondo: República, Sección: Curas y Obispos, Tomo: 25. Folio 524v., AGN. 
ponen en burla la religión por parte de los impíos que llegan al libertinaje. Estos libros, por si fuera poco:

Contienen las máximas de la disolucion y de la impiedad, atentando con esto no solo á la religion y buenas costumbres, sino tambien a la Constitución que gobierna el Estado. [Por tanto] ¿Qué importa que se den á la prensa en Filadelfia, Xamayca, ú otros países, si producen los mismos males efectos que producirán si se imprimiesen en Santafé? ${ }^{54}$.

Parece ser que el provisor Caycedo no recibió respuesta por parte del gobierno, o, de haberla recibido, no habría quedado satisfecho. En octubre de 1823 el ministro fiscal de la Corte Suprema de Justicia del distrito del centro, Ignacio Márquez, dirige oficio al provisor del arzobispado en contra de la decisión de este al publicar en las puertas de la catedral un edicto prohibitivo de la lectura de algunos libros por considerar que no había obtenido licencia del supremo Gobierno. El fiscal le advertía que ni siquiera eran válidas las amenazas de excomunión, por cuanto podía turbar la tranquilidad de las familias.

En interpretación de Ignacio Márquez, las disposiciones de Fernando Caycedo y Flórez:

No puede[n] hacerse sin acuerdo de la autoridad temporal que debe reglar la diciplina externa, y oponerse a cuanto pueda perjudicar a los ciudadanos. Esta facultad que la Yglesia galicana ${ }^{55}$ ha defendido con tanto interés, y que las naciones ilustradas han sabido sostener, como un derecho precioso é inmanente de la soberanía, no ha sido desconocida en España, sin envargo de los delirios de la inquisición, y de la casi ilimitada autoridad de aquel tribunal, como lo convence la ley recopilada. Pretender lo contrario, seria querer arreglar el germen de la discordia en medio de la sociedad, arrebatar al gobierno sus preeminencias, y arrancar a la nación, sus derechos inpresescriptibles ${ }^{56}$.

${ }^{54}$ Arzobispado de Bogotá. "Su comunicación al gobierno sobre introducción de libros obsenos e irreligiosos”, 1823, Fondo: República, Sección: Curas y Obispos, Tomo: 25, Folios 657-658.

55 Como conjunto de ideas político-religiosas, el galicanismo implica que tanto la autoridad de las iglesias locales como del papa se encuentren supeditadas a la autoridad del poder político civil. Su nombre es atribuido a la experiencia del clero francés en "anteponer la Iglesia nacional a la Santa Sede”, lo cual no debe leerse como el rechazo a la doctrina, dogmas y la figura del papa. Ver Cortés Guerrero, La batalla de los siglos, 183, nota al pie 184.

${ }^{56}$ Representación del fiscal José Ignacio Márquez contra un decreto en el que el provisor Fernando Caicedo y Flórez prohíbe unos libros. Incluye: la respuesta del Provisor. Fechada en Santafé, 1823, Fondo: David Mejía Velilla, Sección: Archivo Bernardo J. Caycedo, Serie: Archivo de Fer- 
Estas percepciones de ataque a los principios de la religión y de la jurisdicción eclesiástica que transmiten fray José y el provisor Fernando Caycedo y Flórez, en el año 1824 se vuelven hacia la imprenta con la publicación del semanario El Atalaya y sus 24 números, escrito por un publicista eclesiástico que opta por refugiarse en el anonimato ${ }^{57}$.

Una idea general puede leerse a lo largo de los veinticuatro números: solo la religión cristiana, por ser la única y verdadera por la fuerza que recibe de la revelación, garantiza la estabilidad política de la nueva república, reforzando principios como el bien común, la felicidad universal y la obediencia de los ciudadanos a las autoridades políticas. Para ello, se exponen veinte principios que desarrollan esta idea y que pueden agruparse en cinco temáticas:

i) la existencia de la religión en todas las sociedades por más bárbaras que sean;

ii) la excelencia de la religión cristiana;

iii) la protección que el príncipe debía asegurar a la religión cristiana;

iv) una descripción de las herejías a lo largo de la historia del cristianismo;

v) la defensa de los privilegios eclesiásticos.

A medida que avanza en la argumentación, el publicista clerical advierte con insistencia en la necesidad de contener la emergencia de gentes incrédulas, impías y/o herejes — no existe distinción clara entre ellas - contagiadas por la lectura de filósofos libertinos del siglo XVIII, las cuales propiciarían el caos del orden político por el desconocimiento de la unidad entre cielo y tierra amparada por el Dios cristiano. La inspiración de aquellas gentes se encontraba en el amplio universo de las diferentes herejías de los primeros siglos del cristianismo

nando Caicedo y Flórez, Tomo: 34, Folios: 16-19, Archivo Histórico Cipriano Rodríguez Santa María (AHCRSM), Bogotá-Colombia. Título atribuido:..

57 Semanario impreso en la ciudad de Bogotá en la Imprenta de Espinosa. Por información aportada en el "Prospecto al periódico" se sabe que el semanario circuló también en las ciudades de Medellín, para ser adquirido en casa del cura de Belén, Manuel Rodríguez Obeso; en la de Popayán, en casa del señor Joaquín Gutiérrez; en la de Cali, en casa del cura Juan Ignacio Aragón. Aunque David Bushnell atribuye la autoría de esta publicación al obispo de Popayán, Jiménez de Enciso y Cobos, no aporta mayores datos al respecto. Ver Bushnell, El régimen de Santander, 240. 
definidas y perseguidas por las autoridades eclesiásticas, con ayuda de teológos, a las cuales sumaban el deísmo y el ateísmo como elaboraciones propiamente decimonónicas, que negaban, con mayor soberbia, el dogma de la revelación, fundamento de la fe cristiana.

¿Quiénes eran herejes?: "hombres peregrinos ya sean extrangeros, ya desnatularizados é indignos hijos de la Patria, quienes miran con gran sovervia a todas las instituciones piadosas" ${ }^{8}$. ¿Qué atacaban?: los dogmas de la devoción, la mortificación, la humildad y la pobreza voluntaria. ¿De qué medios se valían?: "[la causa] de la impiedad escandalosa que reina en nuestros días, esta no es otra que la lectura de estos libros prohibidos y anathematizados por la santa Iglesia" 59 .

Y en esta última preocupación se despliega la invitación más fuerte que propone el editor: la censura de los libros de los filósofos impíos, porque evitando el contagio de la irreligión se atacaría el reto del heresiarca y se mantendría la paz y la tranquilidad de la República.

\section{Un religioso herético al final de sus días}

Poco a poco se matiza un desplazamiento de los contornos de la erudición hacia otras formas sociales, y el reto al heresiarca va tomando forma como un asunto de suma relevancia para las autoridades republicanas. Desde 1823, el presbítero Francisco Mariano Fernández se dirigía al vicepresidente Francisco de Paula Santander para solicitar la asignación de pensión vitalicia en reconocimiento por sus servicios como capellán ${ }^{60}$ de las tropas patriotas en territorio caucano,

${ }^{58}$ El Atalaya (Bogotá), n. ${ }^{\circ}$ 15, 1824: 278.

${ }^{59}$ El Atalaya (Bogotá), n. ${ }^{\circ}$ 9, 1824: 148-149.

${ }^{60}$ Sin entrar en mayores especificaciones, Ana María Bidegain señala al respecto que, desde el Río de la Plata hasta el norte de América, el aporte de los clérigos en las guerras de Independencia no solo fue en el "campo intelectual"; antes bien, muchos de ellos participaron activamente como soldados de los ejércitos libertadores, dirigiendo milicias y en la retaguardia, sin hacer distingos "entre la cura de almas y su liderazgo político". Ver "La expresión de corrientes en la Iglesia neogranadina ante el proceso de reformas borbónicas y la emancipación política (1750-1821)", en Historia del cristianismo en Colombia. Corrientes y diversidad, dir. Ana María Bidegain (Bogotá: Taurus, 2004), 170. El historiador Roger Pita Pico, a partir de una aproximación desde la prosopografía histórica, analiza el aporte del franciscano fray Francisco Antonio Florido, y al respecto de su rol como capellán en el bando patriota señala lo siguiente: "en las guerras de Independencia fue una costumbre que los ejércitos estuvieran acompañados de capellanes que se encargaban de los improvisados oficios religiosos y de brindar atención espiritual a los combatientes y a los caídos en el campo de batalla”. Ver Roger Pita Pico, "El cura Francisco Antonio Florido y su aporte al proceso de Independencia 
a las cuales había acompañado desde 1810 hasta 1816, año en el cual fue hecho prisionero por tropas enemigas en la batalla de La Plata. Trasladado en calidad de prisionero a las ciudades de Bogotá y Santa Marta, el tiempo de cautiverio se traduce en la pérdida paulatina del sentido de la vista, quedando así imposibilitado para ejercer las funciones de su ministerio eclesiástico ${ }^{61}$.

La petición es escuchada por el Congreso de la República en decreto publicado con fecha 5 de abril de 1825, que concede la pensión al presbítero por un valor de cincuenta pesos mensuales para el resto de su vida, al estimar sus servicios no solo en el "campo del honor" - ora como oficial del mando, ora como soldado - , sino además sirviendo con su fortuna personal, la cual fue "destinada a la consagración del ejército del Sur" ${ }^{2}$.

Pero la tranquilidad para el presbítero duraría poco. En enero de 1826, el clérigo José Antonio Villalobos presentaba queja ante el provisor del arzobispado de la arquidiócesis de Bogotá, Fernando Caycedo y Flórez, por cuanto el presbítero Francisco Mariano, en conversaciones con el ciudadano José María Guarín Navia, había sostenido las palabras del siguiente tenor: "que Nuestro Señor Jesuchristo no havia resucitado y que su cuerpo se havia consumido como el de los demás hombres" ${ }^{\prime 3}$.

Estas desviaciones de la ortodoxia católica se sumaban a la negativa del presbítero Francisco Mariano de dirigirse a la parroquia de la provincia del Chocó, la cual le había sido asignada por el provisor del arzobispado. Ante la sensación de injusticia, el presbítero dirige recurso de fuerza ante la Alta Corte de Justicia. En el mes de septiembre de 1826 demanda la protección

de Colombia: aproximaciones a las facetas de un patriota integral", 'Ilu. Revista de Ciencias de las Religiones 22 (2017): 303, https://revistas.ucm.es/index.php/ILUR/article/view/57418

${ }^{61}$ Bogotá. Se le concede al Presbítero Francisco Mariano Fernández, el retiro del servicio como Capellán del Ejército (continuación de lo anotado en los folios 135-146), 1829, Fondo: República, Sección: Asuntos criminales, Tomo: 29, Folios: 278 al 289, AGN.

62 "Decreto dado por el vicepresidente de Colombia, Francisco de Paula Santander, por el cual se concede al presbítero Francisco Mariano Fernández una pensión vitalicia. Bogotá, 5 de abril de 1825”, en Codificación Nacional de todas las leyes de Colombia desde el año 1821, hecha conforme a la Ley 13 de 1921, por la Sala de Negocios Generales del Consejo de Estado. Tomo II. Años de 1825 y 1826 (Bogotá: Imprenta Nacional, 1924), 61-62, https://babel.hathitrust.org/ cgi/pt?id=uc1.b5123692\&view=1 up\&seq $=64$

63 "Bogotá. Causa criminal contra el Presbítero Francisco Mariano Fernández, por haber pronunciado expresiones heréticas en contra del Clero (ver folios 278-289)”, 1826, Fondo: República, Sección: Asuntos criminales, Tomo: 29, Folios: 135 al 146. 
de las leyes de la República, indicando que en el territorio designado para sus estipendios eclesiásticos:

donde una buena salud, una vista perspicas y todo cuidado, no bastan a precaver al hombre de las fieras y los reptiles ponsoñonzos que hacen las mas veces el fin de los avitantes de aquellas poblaciones (...) [N]o es presiso hacer muchos comentarios, un ciego es inhábil para todo, no se puede valer a si mismo, menos lo puede hacer para otro, y aun cuando el tacto y abilidad le proporcione algún destino, no puede ser el servicio de párroco, y menos en los mostruosos desiertos del Chocó, donde las vivoras y todo animal ponzoñozo acechan continuamente a la vida del hombre, y condenan a un ciego a ser victima de aquellas fieras, es mas crueldad que la que usaban los romanos poniendo a los delincuentes en el circo ${ }^{64}$.

Con lo que no contaba el presbítero Francisco Mariano era que las autoridades judiciales continuaban informándose acerca de sus aparentes desviaciones de la ortodoxia católica. El día 30 de enero de 1826, comparece el ciudadano José María Guarín Navia ante la Corte, para confesar que preguntándole si creía en la resurrección y asunción de Jesucristo, el presbítero había dicho "que esto era lo que decían pero que el no lo creya" ${ }^{55}$.

El sumario continúa, y en testimonio de María Concepción Rocha para el mes de marzo de 1826, nuevamente ante la Corte, permite a los empleados tomar nota de más errores en las creencias del prelado:

[Q]ue pasando una noche por las tiendas de los señores Torres, estaba en una de las que havita su esposo de ruana, cuyo nombre ignora y le oyo que estaba hechando contra los clerigos, diciendo que estos tomaban el estado por solo el valarze de tener placer y que el [el presbítero Francisco Mariano] havia hecho lo mismo; y que estaban engañando a la gente con un pedaso de pan, que la demandante comprehendio que hablaba de los eucarísticos y que en esto siguió su camino por no oyrlo mas ${ }^{66}$.

Con la dificultad en continuar de manera completa con el sumario por el deterioro biológico de algunos de los documentos luego de unos meses de abierto el proceso judicial, la Corte agrega:

\footnotetext{
64 “Bogotá. Causa criminal”, 1826, República, Asuntos criminales, Tomo 29, fol. 283v., AGN. 65 “Bogotá, Causa criminal”, 1826, República, Asuntos criminales. Tomo 29. Fol.136v., AGN. 66 “Bogotá, Causa criminal”, 1826,, República, Asuntos criminales. Tomo 29. Fol.138r., AGN.
} 
[N]o resultando averiguada la verdad plenamente, pero sí un grave indicio contra el presbitero Francisco Mariano Fernandez sobre las expresiones versiadas por este contra algunos de los principales dogmas de la fe católica, según se ve de la segunda y tercera declaracion: se le absuelve en el presente oficio ${ }^{67}$.

En primer lugar, es difícil no encontrar en los anteriores folios algunas pistas que permitan establecer las creencias religiosas mínimas que establecen el consenso de los fieles en la ciudad de Bogotá, esta vez a partir de la verdad tenida por cierta sobre la resurrección de Jesucristo. En segundo lugar, es igual de pertinente anotar el silencio del provisor Caycedo en asuntos de la ortodoxia, más no así en cuestiones de designaciones de privilegios eclesiásticos como medios de castigos, pues bien advertía el religioso Mariano sobre su avanzado estado de edad. Por otro lado, este conflicto entre el poder judicial y los miembros del clero, esta vez desde la toma de testimonios que dan cuenta de una supuesta desviación religiosa, ayudarían también a fijar una historia más comprehensible de la cultura jurídica republicana ${ }^{68}$. Pero si algo puede servir de diálogo entre las situaciones expuestas es la pervivencia en la sociedad bogotana de los mecanismos de normalización y control de las desviaciones sociorreligiosas, retomando y proponiendo la actualización de la efectividad de la red de personas en conexión a la Inquisición de Cartagena (voluntarios, autoridades civiles y miembros del clero), que en lo cotidiano regulaban el "qué dirán”, es decir, los diferentes juegos de la cultura oral (como el rumor, la pública vos y fama, el chisme o la comidilla) que alimentaban la denuncia ante las autoridades de los supuestos errores en materia de fe por parte de la población ${ }^{69}$.

Otro punto que llama la atención está relacionado con los conflictos de potestades, que si bien no fueron ajenos en las sociedades de Antiguo

67 “Bogotá, Causa criminal”, 1826,, República, Asuntos criminales. Tomo 29. Fol.142v., AGN.

${ }^{68}$ Para la historiadora Diana Paola Herrera Arroyave, el mayor objetivo del nuevo ordenamiento jurídico estaba orientado a la racionalización de la justicia, es decir, "de la capacidad probada del Estado de regular el abanico completo de las prácticas cotidianas y de sustituir aquellos funcionarios de antiguo régimen que se oponían a la administración republicana. Ver Diana Paola Herrera Arroyave, "Orden divino y orden republicano: una disputa por las fuentes del derecho”, Estudios Políticos, n. ${ }^{\circ} 37$ (2010): 158-159, https://revistas.udea.edu.co/ index.php/estudiospoliticos/article/view/8122/0

${ }^{69}$ Diana Luz Ceballos Gómez, “Quyen tal haze que tal pague”. Sociedad y prácticas mágicas en el Nuevo Reino de Granada (Bogotá: Ministerio de Cultura, 2002), 353-369. 
Régimen, muestran la tensión latente por la definición del lugar que debía guardar la religión (creencias e institución) en la nueva comunidad política, así como los esfuerzos cotidianos de las autoridades políticas en presionar a las autoridades eclesiásticas a partir del mensaje del trato no diferenciado, aun cuando estas pudieran demandar a su favor que su apostolado era de naturaleza sagrada, más no temporal. Un último elemento para resaltar está relacionado con la permanencia de la política de la censura y los efectos que de ella se esperan, porque, sin desconocer que la excomunión es siempre una herramienta de persuasión efectiva en manos del clero, se observa la intención de las autoridades republicanas por atajarla a los contornos de lo privado.

Pero al mismo tiempo que se retrotrae a un plano privado el castigo del poder temporal, se amplifica el proyecto de control por parte de las autoridades republicanas, como se muestra a continuación.

\section{Amenazas de cisma en la República}

$\mathrm{Al}$ aproximarse a los años convulsos aquí tratados, la figura del obispo de Popayán, Salvador Jiménez de Enciso no puede dejarse de lado. Llama la atención que un representante del clero que participó en la férrea defensa del rey terminara por reconocer y promover la obediencia al orden republicano, en un tiempo en el que, de un lado, no faltaron destierros a prelados que las autoridades republicanas consideraban aún adeptos a la monarquía, ni tampoco la decisión voluntaria de las altas dignidades en abandonar el virreinato.

Como apoyo al coronel Sebastián de Calzada en la ciudad de Popayán, entre 1818 y 1820 el obispo recaudó auxilios de rentas eclesiásticas y donativos particulares, además de coordinar la movilización de las tropas al lado de los jefes realistas. Con el avance de las tropas patriotas hacia el sur de las Provincias Unidas, el obispo decide retirarse hacia Pasto, ciudad que sirvió de fortín a las tropas realistas, no sin antes excomulgar a quienes habían prestado apoyo a los patriotas criollos, además de cerrar la iglesia catedral y de predicar el desconocimiento a las autoridades eclesiásticas en Bogotá ${ }^{70}$.

En su decisión de abandonar definitivamente su sede episcopal e irse para España, Salvador Jiménez dirige una carta a Simón Bolívar en solicitud de pasaporte, quien responde en carta de 10 de junio de 1822 cuestionándole su decisión al "hacerse sordo al balido de aquellas ovejas afligidas, y a la voz del

${ }^{70}$ Roger Pita Rico, "Clero y lealtades políticas en la independencia: el caso de Salvador Jiménez de Enciso, obispo de Popayán”, Revista Investigium IRE: Ciencias Sociales y Humanas, 8, n.․ㅡ 1 (2017): 51, DOI: https://doi.org/10.15658/INVESTIGIUMIRE.170801.04 
gobierno de Colombia que suplica a V.S.I. que sea uno de sus conductores en la carrera del cielo"71.

Tiempo después, el obispo de Popayán envía una carta a Roma para declarar la conmoción del escrito de Bolívar con el siguiente tenor:

Confieso a Vuestra Santidad que al leer (este) su comunicado, mi alma se conmovió con el recuerdo de mi grey que clama por su pastor, y resolví no abandonarla en su desolación [...] Cuando el Excelentísimo Libertador se dignó visitarme y exponerme de nuevo los argumentos fortisimos que había tocado en su carta, al momento determiné volver a mi diócesis y prestar sumisión y obediencia a la república de Colombia, para poder así emprender nuevamente los trabajos de mi ministerio apostólico ${ }^{72}$.

Esta somera introducción no es gratuita. En carta del día 7 de enero de 1820, el vicepresidente Francisco de Paula de Santander le contaba a Bolívar que "no hay quien se atreva a levantar la excomunión, que impuso este año pasado dejando en la anarquía aquella diócesis" ${ }^{\text {"73 }}$. La resolución del Santander no es menor. Por medio del decreto de 25 de abril de $1821^{74}$ declara la sede vacante del obispado de Popayán como respuesta a la negativa de Salvador Jiménez para retomar a las funciones como obispo. Como el deán a cargo del obispado se negó a nombrar un reemplazo del prelado español, el vicepresidente se acerca al gobernador del arzobispado, Nicolás Cuervo, para que reuniese una junta de teólogos que decretara el extrañamiento del obispado. Esta junta nombra a Manuel María Urrutia como gobernador eclesiástico.

La junta estuvo compuesta por los doctores Pablo Plata, Juan Rocha, José Luis Azuola, Tomás Tenorio, José Ignacio Sanmiguel e Ignacio Herrera. Arremeten contra la disposición de excomunión del obispo de Popayán, al considerarla contraria al juramento de obediencia al gobierno de la república

${ }^{71}$ Citado por Toro Jaramillo, “Clero insurgente”, 135. 4

72 Toro Jaramillo, “Clero insurgente”, 135.

${ }^{73}$ López Domínguez, “Nota Metodológica”, LXX-LXXI.

74 "Decreto dado por el vicepresidente de Colombia, Francisco de Paula Santander, sobre la vacancia del Obispado de Popayán. Bogotá, 25 de abril de 1821", en Codificación Nacional de todas las leyes de Colombia desde el año 1821, hecha conforme a la ley 13 de 1921, por la Sala de Negocios Generales del Consejo de Estado. Tomo I. Años de 1821, 22, 23 y 24. (Bogotá, Imprenta Nacional, 1924): 33-35, https://babel.hathitrust.org/cgi/pt?id=uc1.\$b501358\&view= 1 up\&seq=83 Para este apartado se toma como fuente la justificación extensa que antecede a la declaratoria del decreto. 
que debían prestar los miembros de la institución eclesiástica, tal y como disponían las leyes vigentes. Además, la junta agrega lo siguiente:

4.․ Que el edicto en los términos que está concebido es atentatorio a la autoridad del Gobierno y a la del Metropolitano, y contiene los gérmenes de un cisma perjudicial en lo político, y de funestas consecuencias en lo moral $^{75}$.

Tiempo después de expedido el decreto, y por la dinámica misma de la contienda militar en los territorios del sur del antiguo virreinato, Salvador Jiménez acepta, el 22 de septiembre de 1822, la obligación del juramento a la Constitución Política para ser reconocido en sus funciones eclesiales por parte del Gobierno republicano. Pero más allá de esto, la argumentación de la junta es sugerente en un punto: el cisma no es ya un asunto exclusivamente religioso; es, ante todo, un miedo político, un reto frente al cual las autoridades republicanas deben alzar muros contra todas aquellas disidencias que amenacen en erigirse como diferencias inconciliables.

Como hipótesis para interpretar esta enunciación del “cisma político", un primer lugar por indicar es que si bien existen elementos constitutivos de la herejía (como se explicaron más arriba), el hereje tiene siempre más por decir que lo que un discurso eclesiástico califica como herejía. En este sentido, lo que anuncia una y otra vez el obispo de Popayán con sus prácticas y discursos antes de aceptar el juramento a la Constitución es la inestabilidad del "principio de la unanimidad” sobre el cual se asienta la veritas así como la estabilidad de la jerarquía, otrora eclesiástica, y ahora política. Continuando con el argumento de Jaime Contreras Contreras, el hereje, en tanto disidente y más allá de “cualquiera que fuese su posición doctrinal”, se constituye en peligro al "anular el esquema vertical del tiempo y el espacio jerárquico", los cuales se articularon, en la Europa cristiana, desde la retórica escolástica que rescató la concepción platónica que calificaba lo superior como bueno y lo inferior incuestionablemente malo. Pero no es lo único. De la mano con la sentencia de san Pablo en la carta a los Corintios, II, 19 (“conviene que haya herejes"), fue desplazándose desde la justificación de la existencia de los contenidos doctrinales en la Ecclesia, ante la presencia de sectas, hacia formulaciones en el ámbito del derecho, cuyas

75 “Decreto sobre la vacancia del Obispado de Popayán, 1821”, 35. Llama la atención que el historiador Armando Martínez Garnica hace alusión a este decreto, pero deja de lado la enunciación del cisma político que aquí se problematiza. Ver Martínez Garnica, “La ambición política”, 121-124. 
argumentaciones principales estaban orientadas a "hacer de la disfunción del hereje un delito, y de este un delincuente"76.

¿Acaso es gratuito que sea a través del brazo jurídico del Estado que las enunciaciones de la herejía se hagan circular por diferentes ámbitos? Por lo pronto, las situaciones hasta aquí descritas permiten establecer algunos elementos a través de los cuales la disidencia se pierde en los contornos del delito. Esto contribuye a explicar la siguiente hipótesis. La transición entre el mundo colonial y el republicano supone para la religión católica por lo menos una consecuencia poco notoria, pero no por ello importante de matizar. Es una época de recambios que poco a poco irá haciendo de las "las referencias totalizadoras" y "los discursos dogmáticos" una pluralidad de particularidades. En este orden de ideas, "lo totalizador ya no es sino una parte de un paisaje desordenado que exige otro principio de coherencia" ${ }^{77}$. El paisaje en el cual figura ahora el orden republicano irá acentuando gradualmente una "voluntad de "hacer creer" para darle sustento y forma a la institución [política]"78.

Si el proyecto del orden republicano entre 1819 y 1826 tiene ante sí el reto de hacerse creíble a través de los miembros de la Iglesia institucional, tanto desde su oratoria como de su rol ampliamente reconocido en las comunidades de fieles, esto podría traducirse en que, al contrario de la herejía, el cisma supone dos posiciones, "ninguna de las cuales puede imponer a la otra la ley de su razón o la de su fuerza”. En este orden de ideas, la enunciación del cisma se erige entonces como situación límite que contribuye a interpretar la producción de la herejía, en un periodo en que el Estado procura consolidarse como "la capacidad de ser la unidad referencial para todos" 79 .

\section{Palabras finales}

76 Jaime Contreras Contreras, "Entre tradición y autoridad: la “invención” de la herejía”, en Vivir el Siglo de oro. Poder, cultura e historia en la época moderna. Estudios en homenaje al profesor Ángel Rodríguez Sánchez, Bartolomé Bennassar Perillier et ál. (Salamanca: Ediciones Universidad de Salamanca, 2003), 123-144.

77 Michel de Certeau, La escritura de la historia (México: Universidad Iberoamericana, 2006): 153. Énfasis en el original.

${ }^{78}$ Michel de Certeau, La invención de lo cotidiano 1. Artes de hacer (México: Universidad Iberoamericana, 2010): 194. Énfasis en el original.

${ }^{79}$ Michel de Certeau, “Cristianismo y “modernidad” en la historiografía contemporánea”, en El lugar del otro. Historia religiosa y mística (Buenos Aires: Katz, 2007), 30. 
Las anteriores páginas estuvieron orientadas a proponer algunas significaciones religiosas, sociales y políticas sobre las enunciaciones que suscitan las palabras herejía y cisma para los años posteriores a la victoria militar de Boyacá, la cual supuso un revés en las pretensiones de una reconquista de los dominios españoles, pero que al mismo tiempo abrió la puerta para la construcción de un orden republicano, el cual debía resolver un problema que no resulta menor: hacerse creíble mientras la religión católica se encuentra por fuera de los contornos de la institución eclesiástica y sujeta a las disposiciones del Gobierno republicano. En este sentido, es llamativo que en aquel proceso de hacerse creíble las autoridades republicanas reconozcan la imposibilidad de asegurar la legitimidad ante los antiguos vasallos neogranadinos exclusivamente a través de promesas.

Otro punto que resulta interesante es la ambivalencia de los símbolos y lenguajes religiosos que desde entonces han de configurar las diferentes maneras de religiosidad para aquellos que, por sus condicionamientos sociales, seguirán obedeciendo a las autoridades políticas. En este sentido, se puede proponer que, con la predicación desde el altar, se posicionaron calificativos disponibles desde ahora para los creyentes, quienes cuentan así con repertorios para condenar una acción de Gobierno como contraria a la religión católica y, no menos llamativo, toda máxima política puede ser calificada de herética. Tal vez fue el precio por arriesgar para asegurar la estabilidad de la novedad republicana, la cual no ganaba en demasía con la muerte violenta como medida cohesionadora.

Un tercer aspecto por mencionar es que las enunciaciones de la herejía y del cisma entre 1819 y 1826 se erigen como posibilidades para preguntarnos cuáles son las intenciones tras las condenaciones al error, sobre todo porque lo que está en juego desde ahora es la conflictividad abierta en la carrera de la reafirmación del monopolio de la verdad. Así, mientras estos años anteponen a realistas contra criollos, habría que esperar hacia mediados de siglo para observar la prolongación de contrarios en los calificativos adscritos a movimientos y partidos políticos. Pero, más allá de los reduccionismos ideológicos, y advirtiendo de paso la pluralidad de ideas políticas al interior de una colectividad política misma, lo relevante por destacar es que los enjuiciamientos, condenas y producciones del discurso de las desviaciones, ahora políticas, ahora religiosas, quedarán abierto desde entonces para los actores en escena. 


\section{Bibliografía}

\section{Fuentes primarias}

\section{Manuscritas}

Fondos: República,Asuntos Criminales, Curas y Obispos. Archivo General de la Nación (AGN), Bogotá, Colombia..

Fondo: David Mejía Velilla. Archivo Histórico Cipriano Rodríguez Santa María (AHCRSM). Universidad de la Sabana. Bogotá, Colombia.

\section{Impresas}

Caycedo y Flórez, Fernando. Nos el doctor Fernando Caycedo, y Flores, Arcedeano de esta Santa iglesia metropolitana de Santafe de Bogotá, Provisor, Vicario Jeneral, y Gobernador de su Arzobispado sede vacante. Santafe: Imprenta de la República por Nicomedes Lara, 1823.

Codificación Nacional de todas las leyes de Colombia desde el año 1821, hecha conforme a la Ley 13 de 1921, por la Sala de Negocios Generales del Consejo de Estado. Tomo I. Años de 1821,22,23y 24. Bogotá: Imprenta Nacional, 1924.

Codificación Nacional de todas las leyes de Colombia desde el año 1821, hecha conforme a la ley 13 de 1921, por la Sala de Negocios Generales del Consejo de Estado. Tomo II. Años de 1825 y 1826. Bogotá: Imprenta Nacional, 1924.

"Orden del vicepresidente Francisco de Paula Santander para que todos los párrocos del departamento de Cundinamarca exhorten a sus feligresías sobre la conformidad de la Independencia con la doctrina de Jesucristo" (Santafé, 2 de diciembre de 1819). En Sermones patrióticosen el comienzo de la República de Colombia, 1819-1820. Tomo I. Coordinador por Luis Horacio López Domínguez. Bogotá: Academia Colombia de Historia / Archivo General de la Nación, 2020, CI.

\section{Fuentes secundarias}

Amores Carredano, Juan Bosco. “'Gobernar en justicia'. Realistas y patriotas en Nueva Granada (1810-1816)”, Capítulo VI. En Política y religión en la independencia de la América hispana, eds. Josep-Ignasi Saranyana y Juan Bosco Amores Carredano. Madrid: Biblioteca de Autores Cristianos / Universidad de Navarra, 2011, 131-151

Arce Escobar, Viviana. “La Biblia como fuente de reflexión política en los sermones neogranadinos, 1808-1821”. Revista CS, n. ${ }^{9}$ (2012): 273-308.

."El púlpito entre el temor y la esperanza: ideas de castigo divino y misericordia de Dios en la oratoria sagrada neogranadina, 1808-1820", Anuario de 
Historia Regional y de las Fronteras 17, n. 1 (2012): 77-107. DOI: 10.18273/revanu https://revistas.uis.edu.co/index.php/anuariohistoria/article/view/2705/2982

Bidegain, Ana María. "Los apóstoles de la insurrección y el vicario castrense (18101820)”. Boletín de Historia y Antigüedades 100, n.o856 (2013): 199-237. https:// www.academiahistoria.org.co/boletin/index.php/boletin856/article/view/32/37.

"La Arquidiócesis en el periodo de las guerras de independencia, 1810-

1819”. Capítulo 6 en Arquidiócesis de Bogotá, 450 años: miradas sobre su historia, editado por Jaime Alberto Manceras Casas (Pbro.), Carlos Mario Alzate Montes (O. P.) y Fabián Leonardo Benavides Silva. Bogotá: Universidad Santo Tomás / Arquidiócesis de Bogotá, 2015, 167-204.

"La expresión de corrientes en la Iglesia neogranadina ante el proceso de reformas borbónicas y la emancipación política (1750-1821)”. En Historia del cristianismo en Colombia. Corrientes y diversidad, dirigido por Ana María Bidegain. Bogotá, Taurus, 2004, 145-180.

Bushnell, David. El régimen de Santander en la Nueva Granada. Bogotá: El Áncora, 1985.

Caicedo Osorio, Amanda. Construyendo la hegemonía religiosa: los curas como agentes hegemónicos y mediadores socioculturales (diócesis de Popayán, siglo XVIII). Bogotá: Universidad de los Andes, 2008.

Calderón, María Teresa y Thibaud, Clément. La majestad de los pueblos en la Nueva Granada y Venezuela (1780-1832). Bogotá: Universidad Externado de Colombia, 2010.

Calvo, Nancy. "Los unos y los otros. Católicos, herejes, protestantes, extranjeros. Alcances de la tolerancia religiosa en las primeras décadas del siglo XIX”, Anuario IEHS, n.o21 (2006): 13-35.http://anuarioiehs.unicen.edu.ar/ Files/2006/Los\%20unos\%20y\%20los\%20otros.\%20Católicos,\%20herejes,\%20 protestantes, $\% 20$ extranjeros. $\% 20$ Alcances $\% 20$ de $\% 201 \mathrm{a} \% 20$ tolerancia $\% 20$ religiosa $\% 20$ en $\% 20$ Buenos $\% 20$ Aires $\% 20$ durante $\% 20$ las $\% 20$ primeras $\% 20$ décadas\%20del\%20siglo\%20XIX.pdf

Cavallero, Constanza. Los enemigos del fin del mundo. Judíos, herejes y demonios en el Fortalitium fidei de Alonso de Espina (Castilla, siglo XV). Buenos Aires: Miño y Dávila, 2016.

"La temporalidad del lenguaje de la herejía. El caso de la construcción de la herejía judaizante en el ocaso de la Edad Media”. Medievalismo, n. ${ }^{\mathbf{0}} 22$ (2012): 11-35. https://revistas.um.es/medievalismo/article/view/164311

Ceballos Gómez, Diana Luz. "Política, heterodoxia e Inquisición”. Historia y Sociedad, n. ${ }^{\circ} 22$ (2012): $51-72$. https://revistas.unal.edu.co/index.php/ hisysoc/article/view/32322

Sociedad y prácticas mágicas en el Nuevo Reino de Granada. Bogotá: Ministerio de Cultura, 2002.

Hechicería, brujería e Inquisición en el Nuevo Reino de Granada. Unduelo de imaginarios. Bogotá: Editorial Universidad Nacional de Colombia, 1994. 
Chenu, Marie-Dominique. "Ortodoxia y herejía. El punto de vista del teólogo". En Herejías y sociedades en la Europa preindustrial (siglos XI-XVIII). Comunicacionesy debates del Coloquio de Royaumont, compilado por Jacques Le Goff. Madrid: Siglo Veintiuno, 1987.

Connaughton, Brian. Entre la voz de Dios y el llamado de la patria. Religión, identidad y ciudadanía en México, siglo XIX. México: Fondo de Cultura Económica - Universidad Autónoma Metropolitana, 2016.

"El constitucionalismo político-religioso. La Constitución de Cádiz y sus primeras manifestaciones en el Bajío mexicano y zonas aledañas". Relaciones. Estudios de Historia y Sociedad 37, n. ${ }^{0} 147$ (2016): 85-154. http://www.scielo.org.mx/scielo.php?script=sci_arttext\&pi$\mathrm{d}=$ S0185-39292016000300085\&lng=es\&nrm=iso

"Transiciones en la cultura político/religiosa mexicana, siglo XVII -1860 . El aguijón de la economía política". En Poder civil y catolicismo en México, siglos XVI al XIX, Francisco Javier Cervantes Bello, et ál. México: Benemérita Universidad de Puebla - Universidad Nacional Autónoma de México, 2008, 447-466.

Contreras Contreras, Jaime. "Entre tradición y autoridad: la 'invención’ de la herejía”. En Vivir el Siglo de Oro. Poder, cultura e historia en la época moderna. Estudios en homenaje al profesor Ángel Rodríguez Sánchez. Bartolomé Bennassar Perillier et ál. Salamanca: Ediciones Universidad de Salamanca, 2003, 123-144.

Cortés Guerrero, José David. La batalla de los siglos. Estado, Iglesia y religión en el siglo XIX. De la independencia a la Regeneración. Bogotá: Universidad Nacional de Colombia, 2016.

"Las discusiones del patronato en Colombia en el siglo XIX". Historia Crítica,n. 52 (2014): 99-122. https://doi.org/10.7440/histcrit52.2014.05 "Los sermones en la Independencia colombiana. De la defensa del monarca español a la defensa de la república". En Independencia: historia diversa. Editado por Bernardo Tovar Zambrano. Bogotá: Universidad Nacional de Colombia, 2012, 109-149.

De Certeau, Michel. La escritura de la historia. México: Universidad Iberoamericana, 2006.

De Certeau, Michel. El lugar del otro. Historia religiosa y mística. Buenos Aires: Katz, 2007.

De Certeau, Michel. La invención de lo cotidiano. 1. Artes de hacer. México: Universidad Iberoamericana, 2010.

Di Stefano, Roberto. ¿¿De qué hablamos cuando decimos 'Iglesia'? Reflexiones sobre el uso historiográfico de un término polisémico”. Ariadna histórica.Lenguajes, conceptos ymetáforas, n.․ (2012): 197-202. 
Gacto, Enrique. "Libros venenosos”. Revista de la Inquisición, Intolerancia y Derechos Humanos, n. ${ }^{\circ} 6$ (1997): 7-44.

Garrido, Margarita."Los sermones patrióticos y el nuevo orden en Colombia, 1819-1820". Boletín de Historia y Antigüedades XCI, n.. 826 (2004): 461-483. Guibovich Pérez, Pedro. "La censura de libros". En Literatura y cultura en el Virreinato del Perú: apropiación y diferencia, vol. 2. Coordinado por Raquel Chang-Rodríguez y Carlos García-Bedoya. Alicante: Biblioteca Virtual Miguel de Cervantes, 2017, 55-82. http:// www.cervantesvirtual.com/obra/literatura-y-cultura-en-el-virreinatodel-peru-apropiacion-y-dife-rencia-volumen-2-849332/

Herrejón Peredo, Carlos. "Hidalgo: la justificación de la insurgencia”. Relaciones. Estudios de Historiay Sociedad IV, n. ${ }^{\circ} 13$ (1983): 31-53. https://www. colmich.edu.mx/relaciones25/files/revistas/013/CarlosHerrejon.pdf

Herrera Arroyave, Diana Paola. "La Revolución del cura Botero en Antioquia (Colombia). Una aproximación microhistórica a la disputa por las fuentes del derecho, 1835-1848". Fronteras de la Historia 17, n. ${ }^{\circ} 1$ (2012): 136-166.

."Orden divino y orden republicano: una disputa por las fuentes del derecho”. Estudios Políticos, n.․ 37 (2010): 153-166. https://revistas.udea. edu.co/index.php/estudiospoliticos/article/view/8122/0

Ibarra, Ana ('arolina. "La justicia de la causa: razón y retórica del clero insurgente de la Nueva España”, Anuario de Historia de la Iglesia 17 (2008), 63-80. https://revistas.unav.edu/index.php/anuario-de-historia-iglesia/ article/view/9973

Koselleck, Reinhart. Futuro pasado. Para una semántica de los tiempos históricos. Barcelona: Paidós, 1993.

Lempérière, Annick. “Nación moderna o república barroca? México 1823-1857". En Imaginar la nación. Cuadernos de Historia Latinoamericana n. ${ }^{2}$. Revue de Ahila. Coordinado por François-Xavier Guerra y Mónica Quijada. Münster-Hambourg: 1994, 135-177.

Lida, Miranda. Dos ciudades y un deán. Biografía de Gregorio Funes, 1749-1829. Buenos Aires: Eudeba, 2006.

Londoño Tamayo, Andrés Alejandro. "Juicios de imprenta en Colombia (1821-1851). El jurado popular y el control de los libelos infamatorios". Anuario Colombiano de Historia Social y de la Cultura 40, n.ำ (2013): 75-112. https://revistas.unal.edu.co/index.php/achsc/article/view/38764

López Domínguez, Luis Horario, coord. "Nota metodológica editorial". En Sermones patrióticos en el comienzo de la República de Colombia, 1819-1820, Tomo I. Bogotá: Academia Colombia de Historia / Archivo General de la Nación, 2020, XXVIII-XXIX.

Lynch, John. Dios en el nuevo mundo. Una historia religiosa de América Latina. Barcelona: Crítica, 2012. 
Mallimaci, Fortunato. "Catolicismo y liberalismo: las etapas del enfrentamiento por la definición de la modernidad religiosa en América Latina”. En La modernidad religiosa: Europa Latina y América Latina en perspectiva comparada, coordinado por Jean-Pierre Bastián. México: Fondo de Cultura Económica, 2003, 19-43.

Martínez Garnica, Armando. "La ambición política restringida: la República de Colombia”. Capítulo 2 en Historia de la República de Colombia, 1819-1831. Bogotá: Universidad del Rosario, 2019, 97-232.

"Introducción". En Sermones patrióticos en el comienzo de la República de Colombia, 1819-1820. Tomo I. Coordinado por Luis Horacio López Domínguez. Bogotá: Academia Colombia de Historia / Archivo General de la Nación, 2020, CXLVII-CLXX [147-170].

Muñoz, Fernando. "Aproximación al imaginario religioso del periodo independentista”. Historia y Espacio 6, n. 35 (2010): 177-200. https://historiayespacio.univalle. edu.co/index.php/historia_y_espacio/article/view/1755/1860

Pita Pico, Roger. "La legislación sobre la libertad de imprenta en Colombia en el periodo de Independencia y en la naciente República: convergencias, debates y fluctuaciones". Revista de Estudios Histórico-Jurídicos, n.o 41 (2019): 341-366. https://scielo.conicyt.cl/pdf/rehj/n41/0716-5455-rehj-41-00341.pdf

"Plegarias por la patria libre y soberana. El sermón pronunciado en la Villa de Leiva el 26 de diciembre de 1819". Repertorio Boyacense, 106 (2019): 107-124. https://www.academia.edu/39781982/Plegarias_por_la_patria_libre_y_soberana_el_serm\%C3\%B3n_pronunciado_en_la_Villa_de_Leiva_el_26_de_diciembre_de_1819

"Clero y lealtades políticas en la independencia: el caso de Salvador Jiménez de Enciso, obispo de Popayán". Revista Investigium IRE: Ciencias Sociales y Humanas 8, n. ${ }^{\circ}$ (2017): 46-62. https://doi.org/10.15658/INVESTIGIUMIRE.170801.04 "Conflicto de poderes en torno a las imágenes y alhajas sagradas de los conventos suprimidos en la naciente República de Colombia". Anuario de Historia de la Iglesia, 26 (2017): 351-379. https://doi.org/10.15581/007.26.351-379

"El cura Francisco Antonio Florido y su aporte al proceso de Independencia de Colombia: aproximaciones a las facetas de un patriota integral".'Ilu. Revista de Ciencias de las Religiones, 22 (2017):301.322. https://doi.org/10.5209/ILUR.57418

Plata Quezada, William Elvis, "El catolicismo liberal (o liberalismo católico) en Colombia decimonónica”. Franciscanum. Revista de las ciencias del espíritu 51, n. 152 (2009): 71-132.

Prosperi, Adriano. "El inquisidor como confesor". Stvdia Historica. Historia Moderna, XIII (1995): 61-85. https://gredos.usal.es/bitstream/handle/10366/70045/ El_inquisidor_como_profesor.pdf?Sequence $=1$

Restrepo Posada, José. “. Ilmo. Señor Don Fernando Caycedo y Flórez”. XXXVI en Arquidiócesis de Bogotá. Datos biográficos de sus prelados. Volumen III, 1823-1868. Bogotá: Academia Colombiana de la Historia, 1963, 3-81. 
Saranyana, Josep-Ignasi, director, y Carmen-José Alejos Grau, , coordinadora. “La teología de la independencia”. Capítulo III en Teología en América Latina. Volumen II/2. De las guerras de independencia hasta finales del siglo XIX (1810-1899). Madrid: Universidad de Navarra / Iberoamericana / Verveut, 2008, 189-341.

Séguy, Jean. "La religiosidad no conformista en Occidente". IV en Las religiones constituidas en Occidente y sus contracorrientes. Volumen II, dirigido por Henri-Charles Puech. Madrid: Siglo XXI Editores, 1981, 213-302.

Toro Jaramillo, Iván Darío. "Clero insurgente y clero realista en la Revolución colombiana de la Independencia”. Anuario de Historia de la Iglesia, 17 (2008): 119.136. https://revistas.unav.edu/index.php/anuario-de-historia-iglesia/article/view/9974 Vanegas Useche, Isidro. "El rey ante el tribunal de la revolución: Nueva Granada 1808-1819”. Historia y Sociedad, n.o 31 (2016):17-47. https://doi.org/10.15446/ hys.n31.55457 